\title{
Comparing Student Stage of Reflective Judgment between Junior and Senior Academic Standing
}

Randall C. Miller

West Virginia University

Follow this and additional works at: https://researchrepository.wvu.edu/etd

\section{Recommended Citation}

Miller, Randall C., "Comparing Student Stage of Reflective Judgment between Junior and Senior Academic Standing" (2012). Graduate Theses, Dissertations, and Problem Reports. 617.

https://researchrepository.wvu.edu/etd/617

This Dissertation is protected by copyright and/or related rights. It has been brought to you by the The Research Repository @ WVU with permission from the rights-holder(s). You are free to use this Dissertation in any way that is permitted by the copyright and related rights legislation that applies to your use. For other uses you must obtain permission from the rights-holder(s) directly, unless additional rights are indicated by a Creative Commons license in the record and/ or on the work itself. This Dissertation has been accepted for inclusion in WVU Graduate Theses, Dissertations, and Problem Reports collection by an authorized administrator of The Research Repository @ WVU.

For more information, please contact researchrepository@mail.wvu.edu. 
Comparing Student Stage of Reflective Judgment between Junior and Senior Academic Standing

\author{
Randall C. Miller
}

\author{
Dissertation submitted to the \\ College of Human Resources and Education \\ at West Virginia University \\ in partial fulfillment of the requirements \\ for the degree of
}

\author{
Doctor of Education \\ in \\ Educational Leadership Studies/Higher Education Administration
}

\author{
Sebastian Diaz, Ph.D., J.D., Chair \\ Pamela Whitehouse, Ed.D. \\ Ted Price, Ph.D. \\ Andrea Weber, Ed.D. \\ Steve Robinson, Ph.D.
}

Department of Education

Morgantown, West Virginia
2012

Keywords: Reflective Judgment; Reasoning about Critical Issues Copyright 2012 Randall C. Miller 


\section{ABSTRACT \\ Comparing Student Stage of Reflective Judgment between \\ Junior and Senior Academic Standing}

Randall C. Miller

This study investigated reflective judgment scores of students enrolled in business-related programs of study with junior and senior academic standing from institutions of higher education accredited by the Council of Higher Education in the Mid-Atlantic region of the United States during Fall 2011, Spring 2012 and Summer 2012 semesters. Data were collected from students using a self-administered electronic questionnaire. Student reflective judgment scores were determined by employing the Reasoning about Critical Issues (RCI) questionnaire, a proprietary instrument. Eighty-seven students completed all components of the questionnaire to enable a reflective judgment score to be determined. On average, senior respondents in this study experienced higher RCI scores $(M=4.807, S E=0.120)$ than junior respondents $(M=4.642, S E$ $=0.213)$, although this difference was not statistically significant $(t=-0.725 ; d f=85 ; p=.107)$ and represented a small degree of association $(r=0.012)$. The scores of both junior and senior students were positioned in stage four of reflective judgment with a mean score equaling 4.807 for seniors and 4.642 for juniors; stage four thinking in the Reflective Judgment Model is categorized as quasi-reflective thinking. 
Table of Contents

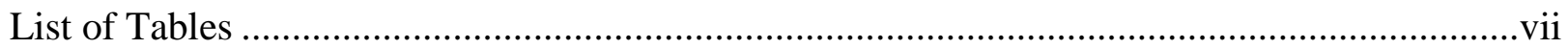

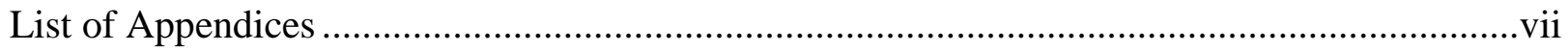

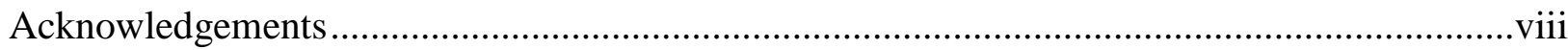

CHAPTER 1 INTRODUCTION ...........................................................................

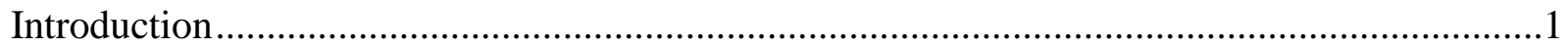

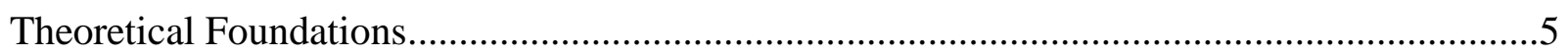

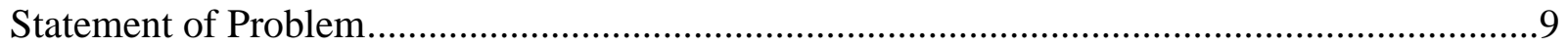

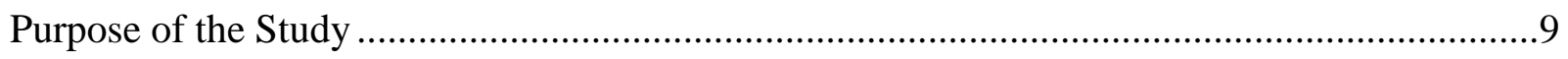

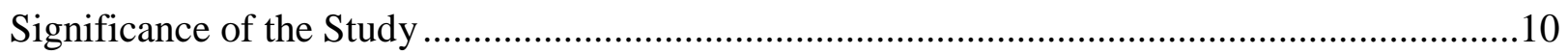

CHAPTER 2 REVIEW OF LITERATURE ............................................................... 11

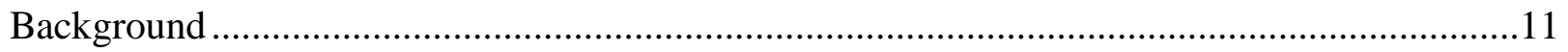

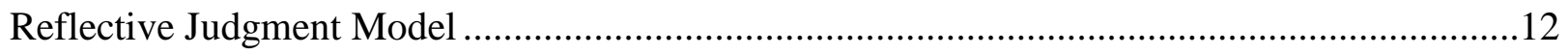

Difference between Reflective Judgment and Critical Thinking .........................................14

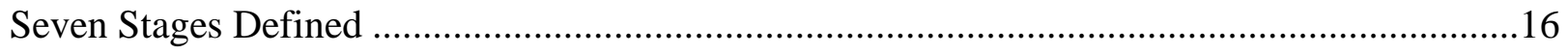

Assessing Levels of Reflective Judgment................................................................. 18

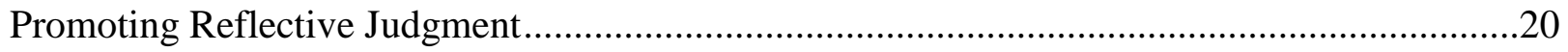

Research using the Reflective Judgment Model ...........................................................23

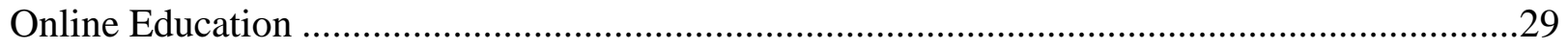

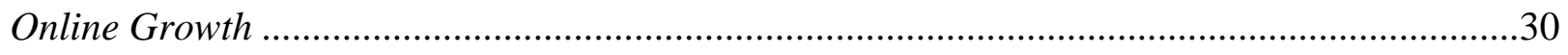

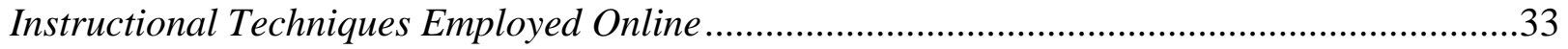

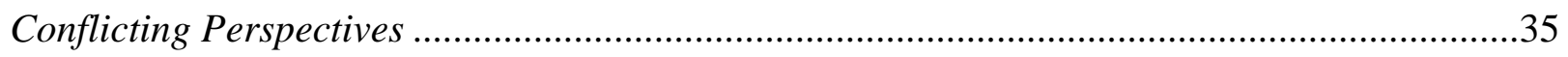

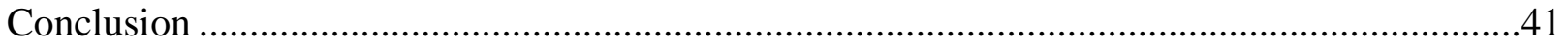


CHAPTER 3 METHODOLOGY

Introduction

Research Design.

Research Question

Independent Variables.

Dependent Variable

Statistical Model

Null Hypothesis

Instrumentation

Matrix of Analysis

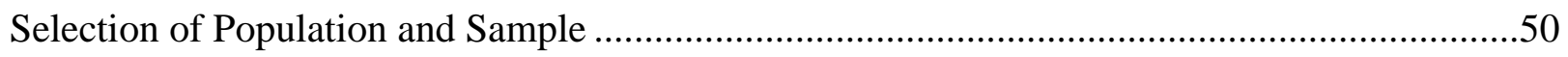

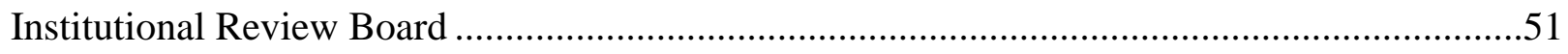

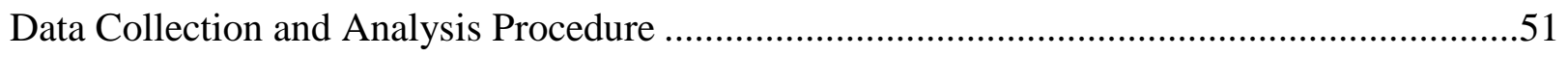

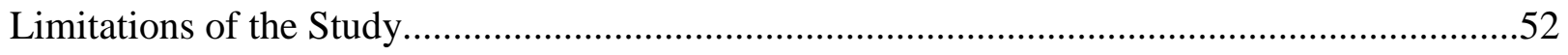

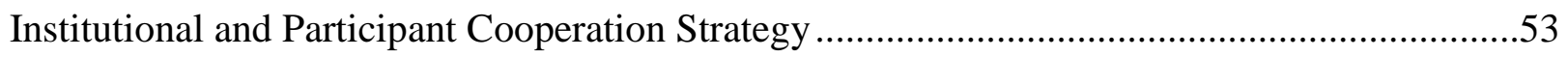

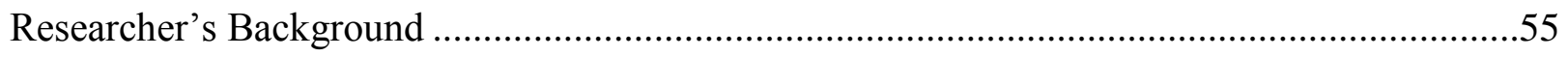

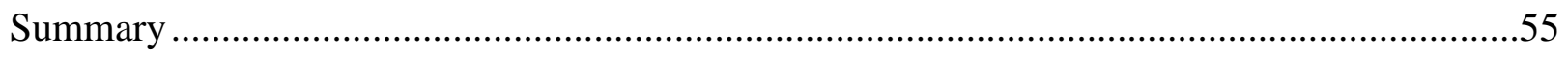

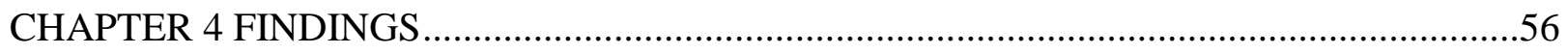

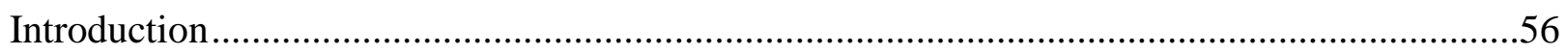

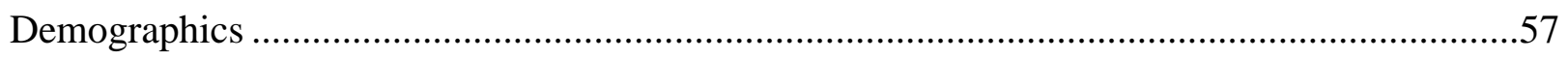

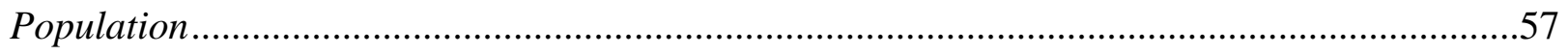

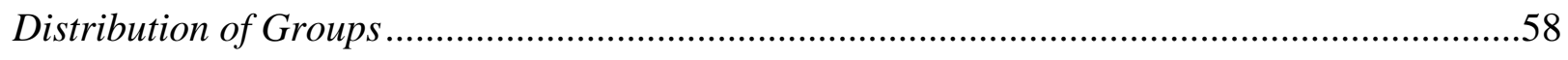

Difference in Reasoning about Critical Issues Scores based on Academic Standing................64 
Other Findings of Differences in Reflective Judgment Score ............................................65

Difference in Reasoning about Critical Issues Scores based on Age Group .............................65

Difference in Reasoning about Critical Issues Scores based on Gender .................................66

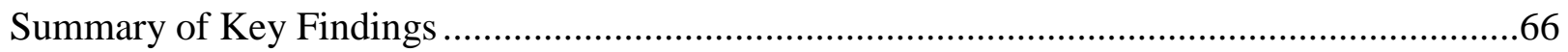

CHAPTER 5 CONCLUSIONS, IMPLICATIONS, AND RECOMMENDATIONS ................68

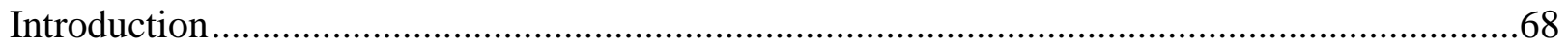

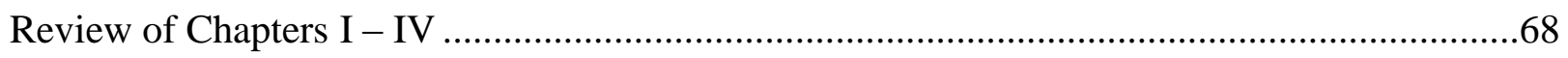

Conclusions Related to Hypothesis ........................................................................ 70

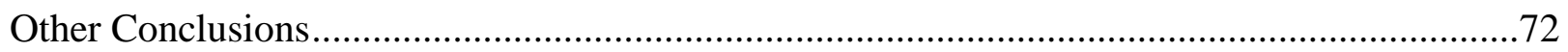

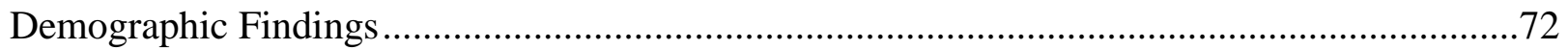

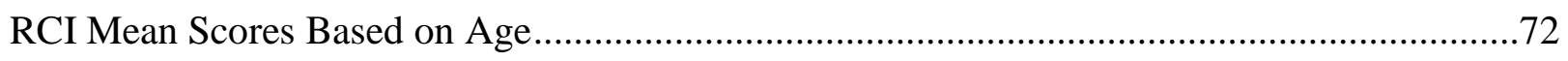

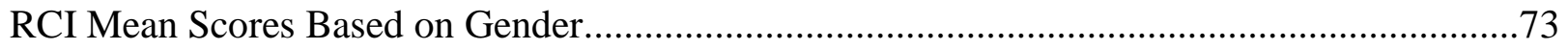

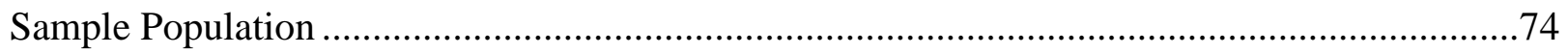

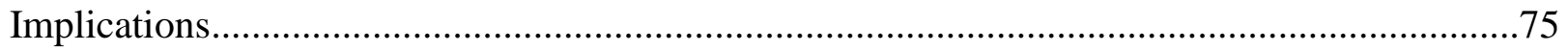

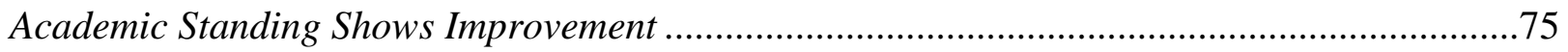

Accompanying Factors Characterize Non-Significant Effect on Reflective Judgment ...............76

Demographic Consideration of Online Population .................................................................76

Larger Sample Size May Improve Significance .............................................................. 77

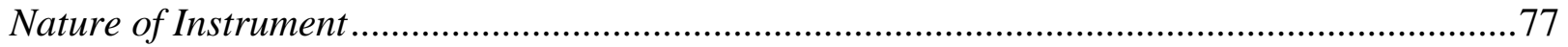

Utilization of Proprietary Instrument in Research ..........................................................79

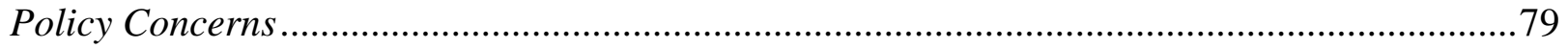

Recommendations for Future Practice ..................................................................... 82

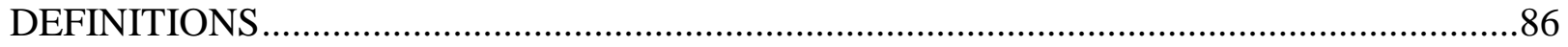




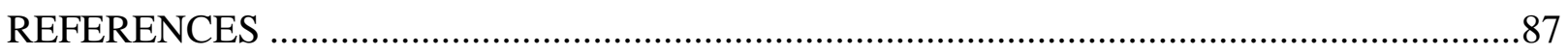

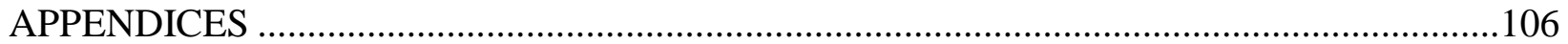




\section{List of Tables}

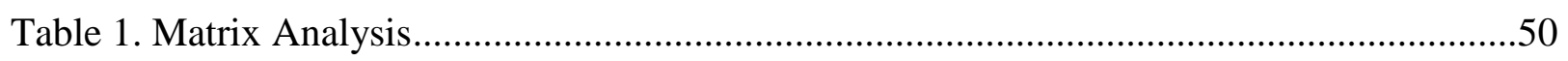

Table 2. Distribution of Data: Academic Standing by Program Delivery Format .....................59

Table 3. Distribution of Data: Academic Standing by Gender .............................................59

Table 4. Distribution of Data: Academic Standing by Age Group........................................60

Table 5. Distribution of Data: Delivery Format by Gender ...............................................61

Table 6. Distribution of Data: Delivery Format by Age Group..........................................61

Table 7. Distribution of Data: Gender by Age Group ...................................................62

Table 8. Distribution of Data: Racial Affiliation by Academic Standing................................63

Table 9. Distribution of Data: Ethnicity by Academic Standing .........................................64

Table 10. RCI Group Mean Score by Academic Standing ...............................................65

Table 11. RCI Group Mean Score by Age Group .........................................................65

Table 12. RCI Group Mean Score by Gender..............................................................66

\section{List of Appendices}

APPENDIX A. Illustration of Reflective Judgment Model................................................106

APPENDIX B. Reasoning about Critical Issues Sample....................................................109

APPENDIX C. Promoting Reflective Thinking .......................................................... 110

APPENDIX D. Institutional Review Board at West Virginia University Approval ..................112

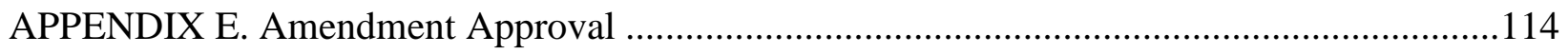

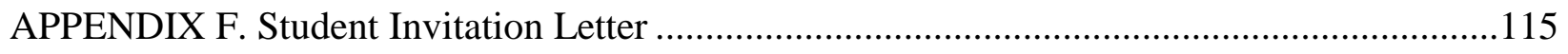




\section{Acknowledgements}

I am truly indebted and thankful to Dr. Sebastian Diaz for taking on the role of Chair for this dissertation and for his support over the past six years of the doctoral program and dissertation study. This dissertation would not have been possible without the continuous support from all members of the dissertation committee, including Sebastian Diaz, Ph.D., J.D, Pamela Whitehouse, Ed.D., Ted Price, Ph.D., Andrea Weber, Ed.D., and Steve Robinson, Ph.D. Thank you for all of your support and guidance.

I would also like thank Dr. Peter G. Checkovich for his continuous support and immeasurable hours of conversation and encouragement, and Brett Caffarelli for proofreading this document and spending countless hours listening to me talk about my research. I am obliged to many of my colleagues, friends, and family who supported me through the doctoral program and dissertation. There are far too many to identify by name or the ways their support made it possible for me to complete this study. Finally, thanks to all Executive Staff members and faculty and staff at Blue Ridge Community and Technical College for encouraging me with many thoughtful insights throughout this study. 


\title{
Chapter I - INTRODUCTION
}

\author{
Introduction
}

The purpose of this study is to determine if stages of reflective judgment differ between students enrolled in traditional baccalaureate programs of study in business-related fields to students enrolled in online baccalaureate programs of study in business-related fields. These fields of study were selected because these programs typically utilize activities that are cited to promote reflective thinking, e.g. case studies, group-work activities, blogs, journaling, research, and discussions (Ilacqua \& Prescott, 2003; Thorseth, 2008). Additionally, students enrolled in business-related programs are likely required to use problem-solving skills regularly, experience a diverse population, face unstructured problems in the workplace, and anticipate future changes in the business environment (Wolcott \& Lynch, 1997). Such a comparison can be significant in an investigation of the linkage between reflective judgment and online course delivery in academic programs in business-related fields.

Driven by factors of equal access to education, flexible scheduling, increasing enrollments, financial stability, competitive advantage, and technological advancement, institutions of higher education are experiencing a time of significant evolution (Geith \& Vignare, 2008; U.S. Department of Education, 2008; Betts, Hartman, \& Oxholm III, 2009; Krakovsky, 2010). These factors have challenged many colleges and universities to investigate opportunities for delivering education in alternative forms in order to keep pace with new developments while improving the quality of educational experiences, addressing appropriate learning outcomes, and maintaining accreditation (Bold, Chenoweth, \& Garimella, 2008). Additionally, academic institutions have been forced to change at a faster rate than experienced historically, and those that do not adapt may lose potential students to competitors (Anakwe, 
Kessler, \& Christensen, 1999). In fact, the impact that technology has on institutions, e.g. administrative communication, instructional communication, and social communication for students and faculty, may even be underestimated by some institutions (Hoy \& Miskel, 2008).

While the ways in which institutions choose to address these challenges may differ, many institutions have chosen to investigate or expand options that offer courses and programs with some features of distance education. Online education, or education that occurs with at least 80 percent of the coursework offered over the Internet, is a commonly chosen method of distance education (Allen \& Seaman, 2007). The term online in this study will thus be used to describe programs that deliver 80 percent or greater of the coursework over the Internet; an alternative to a traditional learning environment, and the term traditional learning environment will be used to describe an educational setting that is conducted with the physical presence of both faculty and students. The major challenge for institutions of higher education is how to address the evolving education landscape by ensuring faculty develop an online culture that provides students with the appropriate environment to support effective cognitive and social development (Whipp \& Lorentz, 2008). When social and cognitive elements interact with the content and are fostered by the learning environment, educational experiences are more meaningful (Seung-won Yoon, 2003; Arbaugh et al., 2008).

Although various forms of distance education, e.g. mail correspondence, television broadcasting, recordings, video conference, have existed for more than 100 years, the recent trend in online education has enhanced enrollment in higher education nationwide (Geith \& Vignare, 2008; Allen \& Seaman, 2010). In fact, online enrollment as a percentage of total enrollment continues to grow, with nearly 30 percent, or over 5.6 million students selecting at least one online course during the fall 2009 term (Allen \& Seaman, 2010). According to Allen 
and Seaman (2010), "slightly more than one-third of all higher education institutions are fully engaged in online education" (p. 24). While this mode of delivering education has stimulated enrollment growth for institutions by providing opportunities for those who would otherwise not attend a college or university, many challenges still exist (Picciano, 2006; Reisetter \& Boris, 2009). One such challenge addresses how to ensure equal opportunities for education to those who reside on the wrong side of the digital divide. It is true that online learning has expanded access to those who cannot attend class on campus, but students from low-income families may not be able to afford the technical hardware and software or Internet access (Allen \& Seaman, 2007; Picciano, Seaman, \& Allen, 2010).

The growing need for online coursework has challenged administrators to select faculty who are skilled in teaching in this environment, to expand instructional design to meet new demands, to invest in the technological infrastructure, e.g. course delivery material, information technology administrative activities, and to hire positions to support faculty and students in this newer academic environment (Picciano, 2006). Additional challenges are posed to faculty who must understand specific instructional strategies for online education, appreciate student perceptions about online education, minimize cheating, and meet the needs of students who are diverse in terms of academic, social, and technical abilities (Ukpokodu, 2010).

Although education may be delivered in an online setting, as with traditional learning environments, effective communication is necessary. Institutions attempt to stay connected with students through synchronous and asynchronous mechanisms by facilitating classroom discussions, encouraging cooperative learning, and through online submission of assignments (Shambaugh \& Magliaro, 2006). The synchronous environment is intended to mimic a traditional classroom setting and requires students to respond immediately to online 
communication in an impromptu fashion. The asynchronous learning environment allows for students to complete homework, communicate with peers and the instructor, and submit assignments at a time that is convenient, thus allowing a student to reflect on an assignment or communication, and to take the time to check for understanding of the content prior to responding (Knowlton, 2009). Additionally, the online environment provides flexibility for students who wish to set their own schedule or are not capable of driving to campus as often as required in traditional face-to-face classes (Knowlton, 2009). While students enjoy a flexible assignment schedule, it is important that instructors clearly outline and communicate the criteria utilized to evaluate students in both asynchronous and synchronous learning environments to ensure students stay focused and are aware of expectations for online participation (Knowlton, 2009).

The significant challenge facing institutions that employ online academic coursework is to ensure students adequately develop a cognitive capacity to make critical and analytical reflective judgment decisions. Reflective thinking, as described by Dewey (1933) is "the better way of thinking ... the kind of thinking that consists in turning a subject over in the mind and giving it serious and consecutive consideration" (p. 3). Generally, researchers find that the development of reflective thinking is strongly supported by quality educational programs (King \& Kitchener, 2004). While many articles and studies have provided pedagogical strategies that enhance learning, critical thinking, and reflective judgment practices in traditional and online academic programs, little research has been completed to compare stages of reflective judgment between online and traditional learning environments. Ensuring students are equipped with the knowledge and capacity to make ethical and reflective decisions should not only be a goal but a requirement of institutions of higher education (King \& Kitchener, 1994). Guided by King and 
Kitchener's Reflective Judgment Model (RJM), this research will help to foster this understanding by investigating reflective judgment scores of students enrolled in online and traditional programs of study in business-related fields.

Even though the online method of delivering education has grown continuously for many years, a segment of academic professionals still consider that online education "goes against the very nature of what they are trying to achieve at their institution" (Allen \& Seaman, 2007, p.8). Some faculty have a disdain for technology and do not employ technological tools to support learning because they believe students will pick up these technology skills in other courses (Shambaugh \& Magliaro, 2006). The institutions that will be most successful in this new, technologically-advanced academic setting, "will be those that increase their emphasis on providing a high-quality education using the best technology available" (Hiltz \& Turoff, 2005, p. 63 ) in conjunction with employing appropriate pedagogical strategies that utilize effective course management designs, and effectively facilitate learning by faculty. The emphasis of this study is not to address all issues that faculty have with online education, but to compare reflective judgment for students enrolled in traditional academic programs in business-related fields with students enrolled in online programs of study in business-related fields.

\section{Theoretical Foundations}

The framework for this research is provided by Patricia King and Karen Kitchener's model of reflective judgment which "describes a sequence of changes in thinking that affects the ways students justify their beliefs and make judgments" (Patricia King, 1992, p. 2). Since "traditional - age[d] students attend college at a time when they are actively experimenting with and consolidating a sense of identity" (King \& Kitchener, 1994, p. 203), this emphasizes the 
stages of traditional-aged students' intellectual development between face-to-face and online delivery formats.

King and Kitchener's model stems from previous research in education and shares elements of stage-related development with Piaget, a process of successive advancement of students' beliefs about their own awareness and values with Perry, as well as an operationalized definition of reflective thinking with Dewey. The model supports college faculty and administration in understanding how students in higher education assess their own learning. This study will expand current research on student development by comparing stages of reflective judgment between traditional and online academic programs and examines whether stages of reflective judgment are comparable, regardless of delivery modes (King, 1992).

The levels of understanding for ill-structured problems are demonstrated in the reflective judgment model which provides an increasing sequence of seven stages (King \& Kitchener, 1994, 2004). Each stage is distinguished from the rest, and increases through individual assumptions of understanding and evaluations. "Longitudinal studies have consistently shown upward changes in reflective judgment over time, especially among individuals involved in educational endeavors" (King, 2000, p. 21). Additional research in higher education shows that reflective judgment scores tend to increase between college freshmen and senior samples (Wolcott \& Lynch, 1997; Friedman, 2004). This trend begins with high school samples and continues through graduate student samples (King \& Kitchener, 2004). While education has a strong correlation with an individual's progression through the stages, the exponential growth of online course offerings provides an interesting opportunity to understand the potential differences in development during the college years when comparing alternative forms of delivery. Considering the expansion of globalization and strengthening of technological network 
structures throughout the world, online education and the need to serve a broader student population may become the norm in education for the future (Lynch, 2004).

The theoretical foundation of reflective judgment, "the observation that uncertainty is a characteristic of the search for knowledge," (Dewey, 1933) has been discussed by a number of researchers. Drawn from theorists and developmental psychologists such as Dewey, Piaget, Flavell, Perry, Broughton, Fischer, and Kegan, and directed by King and Kitchener's observation that an individuals' assumptions of their own cognition plays a factor in how they substantiate their views, and recognizing that these assumptions develop sequentially over time, the RJM was established to describe how cognitive development of reflective judgment takes place in adolescents and adults (King \& Kitchener, 1994). The RJM is intended to score levels of reflective thinking into stage-related development that occurs sequentially and logically in college students in the pursuit of educational experiences (Dewey, 1933; Piaget, 1969). Individuals score in the pre-reflective stages during early childhood and adolescence, and begin to develop differently through increasing stages of cognitive development in a sequence as a result of educational experiences (Kohlberg, 1984). Although an individual may appear to be in one stage depending upon the situation, they may exhibit characteristics of another stage in another situation. This is characterized by the individual's optimal range and functional levels (Fischer, 1980; Lamborn \& Fischer, 1988). Through educational and individual experiences, a person evolves from relying on knowledge from authority figures which they believe to be the source of true knowledge, to understanding that knowledge is constructed through research and reflective thinking about experiences (Kegan, 1982).

The stages within the RJM aid in understanding how individuals make decisions on topics that are not known or ill-structured. According to King and Kitchener (2004), those 
exhibiting characteristics of stage one can be described as "I know what I have seen" (p. 7). Individuals in stage two believe that "if it is on the news, it has to be true" (p. 7). Stage three thinking can be characterized as "where there is evidence that people can give to convince everybody one way or another, then it will be knowledge, until then, it is just a guess" (p. 8). Stage four individuals thinking is characterized as "I would be more inclined to believe evolution if they had proof" (p. 7). Stage five thinkers believe that "[p]eople think differently and so they attack the problem differently" (p. 7). Stage six thinkers believe "[i]t is very difficult in this life to be sure" (p. 7). And, finally, stage seven reflective thinking can be characterized as believing "[o]ne can judge an argument by how well thought-out the positions are, what kinds of reasoning and evidence are used to support it, and how consistent the way one argues on this topic is as compared with how one argues on other topics" (p. 7). A summary of King and Kitchener's RJM is illustrated in Appendix A which shows organization of seven stages arranged in three categories.

In addition to comparing variation in reflective judgment stages between the two groups, the typical stages exhibited by college students through the work of King and Kitchener should be noted; in a cross-sectional study that reviewed 25 previous studies showed a mean score of 3.6 for freshmen and 4.0 for seniors (King \& Kitchener, 2004). The aim of this research is to determine if the students in this study score at similar levels by comparing scores of juniors and seniors enrolled in online and traditional programs of study. It is important to select participants who have enrolled in predominately online courses to fully understand some of the affects of online course delivery. While reflective judgment may increase in a span of one semester, the focus of this study is to compare students enrolled in online programs of study to those enrolled 
in traditional programs of study during junior and senior years in order to investigate the influence of program delivery format and class rank on reflective judgment.

\section{Statement of the Problem}

While many studies have researched differences between online and traditional learning environments, as well as identified ways to improve students' cognitive development and, specifically, reflective thinking in traditional environments, research that compares student stages of reflective thinking between traditional and online modes of delivery is lacking. This research addresses factors of cognitive development by comparing students' reflective judgment development in traditional and online academic programs, as well as reviewing pedagogical strategies used to enhance reflective judgment in each mode of delivery.

\section{Purpose of the Study}

The purpose of this study is to determine if stages of reflective judgment differ between students enrolled in traditional baccalaureate programs of study in business-related fields to students enrolled in online baccalaureate programs of study in business-related fields. The study also gathered demographic data to investigate similarities and differences among students selecting the chosen mode of delivery in order to isolate any selection criteria that may exist. The goal of this study is not to distinguish if one form of delivery is superior to the other, instead this study attempted to determine if a statistically significant difference in reflective judgment scores exists.

The following research question will guide the study:

- What are the differences among reflective judgment scores of students enrolled in business-related programs due to factors of class rank and program delivery format? 


\section{Significance of the Study}

This study will examine if the reflective judgment stage exhibited by students enrolled in traditional baccalaureate programs of study in business-related fields differs from students enrolled in online baccalaureate programs of study in business-related fields at colleges and universities in the United States. The intent of this study is to add to research previously completed for online education and reflective judgment, and to provide insight as to whether reflective judgment demonstrated by students completing education through online academic programs is comparable to students completing traditional academic programs.

The rapid rate of development and interest of educational technology has provided faculty with methods and systems to employ before scholars have fully begun to examine the success of such technology for learning (Rogers, Graham, \& Mayes, 2007). Consequently, academics should thoroughly research the effectiveness of employing online tools for learning and contribute to research in the field of educational technology. According to Angiello (2010), minimal research about the effectiveness of online learning exists and is necessary before institutions contribute large quantities of funds toward online learning. King and Kitchener (2004) assert that linking experiences gained through collegiate activities to student development would contribute to gaining further awareness about the process of enhancing reflective thinking in higher education. Therefore, the real value of this study is that it contributes to the growing literature on reflective judgment and online delivery modes that are quickly penetrating all levels of education. 


\section{Chapter II - REVIEW OF LITERATURE}

\section{Background}

As institutions of higher education examine ways to reduce costs, expand course offerings, increase accessibility, and meet the multitude of needs and expectations of the community in various modalities, faculty and administrators in higher education must be certain that programs of study remain student-centered to target effective learning. Advancements in technology have allowed institutions to meet many of these challenges by implementing technology-mediated classes through hybrid or blended courses, distance education, and online classes delivered over the Internet. Many faculty question the effectiveness of using technology in place of classroom instruction, while others feel that instruction is just as effective in an online environment when incorporating necessary adaptations (Reisetter \& Boris, 2009). Some studies indicate that online learning may be less effective under particular circumstances; and, still, others have recently argued that aspects of online education are more effective than instruction in a traditional learning environment. The true value of technology employed in an online environment is only as effective as the reliability of the tool and its capacity to support student interaction (Seung-won Yoon, 2003). The majority of these studies define effectiveness as the ability of the faculty to accomplish course objectives and the ability of students to successfully demonstrate learning outcomes. While this study will not settle the debate of traditional versus online learning, it will contribute to the research through a focus on reflective judgment by comparing Reflective Judgment Model (RJM) mean scores of students enrolled online, with students enrolled in a similar program, but in a traditional mode.

In order to effectively educate students and prepare them to become reflective thinkers, faculty must understand and possess the ability to support this development and remain 
committed to the learning process in an online environment in the same capacity as faculty who educate in a traditional learning environment. This chapter reviews the importance that reflective judgment has on student decision making, including how it is obtained, its importance in higher education, and ways that college educators may take action to support progress of reflective thinking (Huba \& Freed, 2000). Existing research that examines the effectiveness of online learning in higher education is covered, as well as additional studies with an emphasis on reflective judgment in a traditional setting. And lastly, faculty, student, and public perceptions of online learning are discussed. The chapter concludes with a brief comparison of online and traditional learning environments relevant to the study.

\section{Reflective Judgment Model}

Reflective judgment can be best described as " $[\mathrm{t}]$ he kind of thinking that consists in turning a subject over in the mind and giving it serious and consecutive consideration" (Dewey, 1933, p. 3). Reflective judgment has been studied in many educational contexts - especially in the traditional classroom - as a way to understand how students think, how students develop into reflective thinkers, and what activities can be employed during the college experience to promote higher levels of reflective thinking. For example, in a 10-year longitudinal study, King and Kitchener (2004) revealed that levels of reflective judgment increased through educational activities for high school, college, and doctoral students, as measured using the RJM.

The RJM “is based on Perry's work on reflective thinking as well as works by a variety of philosophers and has undergone further development since the authors' first study of reflective judgment" (van Aalst, 2006, p. 2), which ensures the model has been thoroughly researched and validated by theorists and, thus, provides an adequate theory to be used for this study. The model also borrows from Piaget's analysis that development of individual intellect 
evolves over a period of time through experiences and involvement with their surroundings, but differs from Piaget's view that logical thought materializes by age 16 in the formal operations stage and "that cognitive development is best measured by deductive reasoning" (King \& Kitchener, 2004, p. 9). Similar to Kohlberg's stage-based model, the RJM progresses rationally from lower stages to higher and more complex stages in an organized manner without skipping a stage, and is similar to Rest's view that development occurs in complex rather than simple stages (King \& Kitchener, 2004). In a complex stage model, students may exhibit characteristics of multiple stages rather than being classified as residing in a single stage. King and Kitchener (1994) describe this development as:

waves across a mixture of stages, where the peak of a wave is the most commonly used set of assumptions. While there is still an observable pattern to the movement between the stages, this developmental movement is better described as the changing shape of the wave rather than as a pattern of uniform steps interspersed with plateaus. (p. 140) Each sequential stage builds upon the previous stage in which an individual employs more complex strategies for generating assumptions and defending and assessing decisions about ill-structured problems, all of which improve as an individual displays the ability to think reflectively. These types of problems are described by King and Kitchener (1994) as vexing problems, the types of problems that are not solved by applying predetermined steps or formulas to reach a correct answer. Instead, individuals must use "coherence of the argument, fit with other data and arguments, explanatory power of the solution, plausibility, and so on" (King \& Kitchener, 1994, p. 7) to arrive at a thoughtful and reflective conclusion. It is this type of problem that distinguishes reflective thinking from critical thinking. 


\section{Difference between Reflective Judgment and Critical Thinking}

While many of the characteristics of reflective thinking are also present in critical thinking, and while it could be said that the RJM also measures aspects of critical thinking, the two constructs are not the same, nor does the RJM measure critical thinking alone. Reflective judgment is more focused on the process of consideration a student explores to critically analyze ill-structured problems (Kroll, 1992). King and Kitchener (1994) identify two main differences between reflective judgment and critical thinking: "the epistemological assumptions on which the thinking person operates and the structure of the problem being addressed" (p. 8). Considering epistemological assumptions, when individuals are thinking critically they are using a set of guidelines or predetermined steps to move toward a conclusion with the purpose of generating the correct answer for the situation. Learning to employ these steps can be taught through direct instruction, and it is easy to identify where an individual concluded with an erroneous resolution in the decision making process. In contrast, reflective judgment is gained through personal experience; experiences with family and friends, teachings from instructors and other experts, and research conducted, all combined to help individuals solve ill-structured problems that may not have a single defined solution (Braxton, Hirschy, \& McClendon, 2004; Downey, 2002). In other words, critical thinking is "about what can be known" and reflective judgment is "how knowing occurs" (King \& Kitchener, 1994, p.9). While epistemological development is shown to be linked to the way in which people defend their thinking about vexing problems, simply "using either deductive or inductive logic does not account for the differences in epistemological assumptions even at early levels" (King \& Kitchener, 2004, p. 41) in reflective judgment. Because controversial problems cannot always be completely defined or 
solved with absolute certainty, simply possessing the ability to think critically will not often suffice in many real-world problems (King \& Kitchener, 2004; Pascarella \& Terenzini, 2005). As related to a problem's structure, critical thinking involves solving problems in a logical order while reflective thinking occurs in situations without authoritative answers. Churchman (1971) refers to matters considered when thinking critically as well-structured problems, meaning the problems can be solved by using strategies or steps to come to an ultimate answer. Various assessments have been designed to measure an individual's level of critical thinking such as the Watson-Glaser Critical Thinking Appraisal (WGCTA) and the Cornell Critical Thinking Test (CCTT); however, the correlation between these tests and the Reflective Judgment Interview (RJI), which is used to identify stages of RJM, were low (King \& Kitchener, 1994). These assessments have also shown that "while the development of critical thinking skills may not continue into early college years, development of reflective judgment clearly does so" (King \& Kitchener, 1994, p. 192).

Further research has shown that critical thinking skills are associated with reflective judgment, and are necessary, but not exclusively sufficient, to achieve reflective judgment (Kitchener \& Wood, 1987; King \& Kitchener, 1994; Bauer, 2001). Reflective thinking, on the other hand, is used to solve problems without definitive answers, such as evolution. Another way to recognize an ill-structured problem is to ask the question: do experts in the field have different solutions to the problem? If so, then the problem is most likely an ill-structured problem (Wolcott \& Lynch, 1997). As stated by King and Kitchener (1994), "reflective judgment is called for only in those situations in which there is real uncertainty, assumptions about what can be known, and how a person can know" (p. 18 - 19). 


\section{Seven Stages Defined}

The RJM employs a seven-stage model where as individuals progress through stages, lesser reasoning is replaced with higher reasoning (Davison, King, Kitchener, \& Parker, 1980). These seven stages are categorized in three levels of reflective judgment: pre-reflective, quasireflective, and reflective. The first level within RJM is the pre-reflective level, which includes stages one through three. Individuals in the pre-reflective stage have yet to understand that knowledge is not always certain (Evans, Forney, \& Guido-DiBrito, 1998). They are not able to recognize that a given problem may have more than one correct answer (Wood, 1997). Individuals exhibiting stage one characteristics of RJM believe knowledge is gained through sight (i.e. "what I have seen is true") (King \& Kitchener, 1994, p. 47) and have difficulty if presented with a competing view. Individuals in stage two also gain understanding through what they see, but expand their search to obtain answers from experts. Similar to stage one, knowledge in stage two is fixed but when faced with a problem for which they cannot find the answer, the individual comes to the conclusion that experts have not had the time to find the answer. Those in stage three of the RJM also share the belief that knowledge is certain, but in cases when experts have not found answers the individual relies on their own personal judgment. In these cases, the individual still believes the experts will eventually find a correct answer, but struggles in making the connection that some problems do not have a definitive answer (King \& Kitchener, 1994). Continuing with this study, King and Kitchener's and other's studies show that freshmen RJM scores average 3.6, while senior samples show a median score of 4.0. While only a modest difference is shown between the freshmen and senior years, the differentiation between the way of thinking evident in stage three and stage four are significant and important to note (King \& Kitchener, 1994; Pascarella \& Terezini, 2005). The significance in the quantitative 
size of change is less significant than the qualitative change in thinking that occurs at this level (Pascarella \& Terezini, 2005).

In stages four and five, individuals begin to understand that there are problems which do not have a single, correct answer or solution. Individuals in these stages are classified in the RJM as quasi-reflective thinkers. Individuals with quasi-reflective thinking recognize that illstructured problems may not have one correct answer, but struggle to differentiate personal beliefs from organized and produced analysis and conclusions (Wood, 1997). While individual understanding has expanded to recognize that ill-structured problems exist, they are unable to use data appropriately in order to draw conclusions (Evans et al., 1998). Individuals in stage four justify answers when evaluating data in an individual manner, "choosing evidence that fits an established belief' (King \& Kitchener, 1994, p. 61), and when faced with opinions that differ from their own they draw the conclusion that others must have misinterpreted the data to reach a different conclusion. Individuals in stage four thinking "resolve ill-structured problems by shifting focus, [in stage five] the shift is from examining how knowledge is justified within one context to how it is justified within another context” (King \& Kitchener, 1994, p. 63).

The final stages of the RJM, stages six and seven, are categorized as reflective thinking. In these stages, one's understanding moves beyond devising an appropriate approach to illstructured problems "to the ability to evaluate the general adequacy of an approach relative to other logical, internally consistent approaches" (Wood, 1997, p. 5). Individuals are capable of resolving that not all problems can be answered with absolute sureness, and evidence can be utilized to reach rational conclusions. Individuals exemplifying stage six characteristics begin to compare and evaluate data with other views to draw a more complete conclusion. They also abandon the idea that evidence is either right or wrong and begin to differentiate between weak 
and strong arguments giving them the opportunity to make better-informed decisions (King \& Kitchener, 1994). The final stage in the RJM, stage seven, is the point where the individual demonstrates true reflective judgment. Individuals demonstrating stage seven characteristics understand that knowledge is always evolving and that they too must evolve and continue to review their previous notions. These individuals understand that the knowledge they currently possess may be outdated by future enlightenment or evidence (King \& Kitchener, 1994).

\section{Assessing Levels of Reflective Judgment}

Three tools have been developed to assess RJM, and provide a way to understand changes in reflective thinking that occur during educational experiences. Neither instrument is designed to obtain factual knowledge from participants; rather the instruments are designed to detect cognitive processes as well as modes of reasoning used to produce responses to illstructured problems. The RJI and RCI measure the functional level rather than optimal level of reflective judgment from respondents. The functional level is the level at which a respondent scores when faced with an unfamiliar ill-structured problem, while the optimal level is exhibited when the respondent is presented with a question as well as the reinforcement necessary for the respondent to contextualize the question (Fischer, 1980). As reported by King and Magolda (1996), an individual is capable of more complex thinking when they receive the necessary support. Kitchener, Lynch, Fischer, and Wood (1993) conducted a study that compared participant response on the Reflective Judgment Interview (RJI) to response on a Prototypic Reflective Judgment Interview (PRJI). The PRJI was designed to provide participants with support statements and practice in order to contextualize and familiarize the participant with the types of questions asked in the interview protocol. The PRJI was believed to measure the participant's optimal level, rather than the functional level that is measured with the RJI. 
Several features have been identified by King and Kitchener as necessities of any instrument employed to assess RJM:

- The instrument must focus on ill-structured tasks.

- The instrument must extract a reply about the rationale and content of responses.

- The instrument must provide for judgment across a diversity of topics.

- The topics must be general in nature that a wide range of individuals share some level of familiarity with the topic.

- The topic should not limit respondents to educational settings.

- The reading level must be low enough that a broad range of respondents may participate.

- The instrument must be validated (van Aalst \& Katz, 1999).

The RJI is a qualitative tool designed to capture responses from participants in order to identify the process that each individual uses to address ill-structured problems. This tool has been validated through extensive research and was used by King and Kitchener in their initial longitudinal study of reflective judgment. This tool is a production task type of instrument and is scored by trained interviewers based on the respondent's reply to a set of predetermined questions. This allows the interviewer to obtain responses that are produced spontaneously based on the respondent's range of reasoning capabilities (King, 1990). The RJI allows for assessment of individual assumptions and can support attainment of scores across all seven stages of the RJM.

Modeled after Rest's Defining Issues Test (DIT), the more recently produced Reasoning about Current Issues (RCI) assessment is a quantitative questionnaire that provides an alternative to the RJI (King \& Kitchener, 2004). Unlike the RJI, the RCI does not allow researchers to establish inferences about individual responses; rather the instrument should only be used when 
comparing groups (www.reflectivejudgment.org). The RCI uses one of three predesigned questionnaires that pose responses to ill-structured problems and allow respondents to select a response that most closely represents their own response. This allows for scoring of respondents in reflective judgment stages two through seven. "The RCI is based on research using the RJI, is grounded in the same theoretical framework, and provides a promising tool for assessing the Reflective Judgment Model" (htp://www.reflectivejudgment.org). A sample of the RCI appears in Appendix B.

The RCI is comprised of four sets of questions: the first question uses a likert scale to obtain the respondent's opinion on one of three topics; work force, alcoholism, or immigration. Next respondents must write a response to describe how they feel it is likely that differing opinions exist among professionals in the field. Then respondents use a likert scale to indicate how similar their responses are to a set of predesigned statements regarding the topic. Lastly, respondents rank the top three of ten questions in the order of how closely related they are to their own opinions of the topic. Minimal demographic data is also obtained to allow for further analysis.

\section{Promoting Reflective Judgment}

According to King and Kitchener (1994), several assumptions are considered when promoting reflective judgment:

- individuals actively interpret and attempt to make sense of what they experience,

- the way individuals interpret events is affected by their epistemic assumptions,

- people's way of making meaning develop over time,

- individuals function within a "developmental range" of stages,

- interactions with the environment strongly affect an individual's development, 
- development is stimulated when an individual's experiences do not match his or her expectations, and

- development in reflective thinking occurs within the context of the individual's background, previous educational experiences, and current life situation (p. 226-229). The RJM is based on the notion that "[a]s individuals develop, they become better able to evaluate knowledge claims and to explain and defend their points of view on controversial issues" (King \& Kitchener, 1994, p. 13). This ability supports student development in all areas of academic life and is not only advantageous in the field of study being pursued by the student, but also expands to include the ability to make more informed decisions in everyday life. Thus reflective judgment should not only be promoted throughout the designed curriculum, it should also be pursued in all co-curricular activities that engage students on campus (King \& Kitchener, 1994). The necessity to engage students in activities that occur outside of the classroom is strongly emphasized for administration and student affairs departments across campuses. Thus, better development of understanding and reasoning doesn't simply occur in the classroom, but in a holistic nature of events, activities, and experiences students engage in during college (King 2000). Reflective judgment skills have been shown to be applicable in supporting multicultural education where students encounter diverse populations in clubs, fraternities, sororities, and other organizations on campus (King \& Shuford, 1996). This means that reflective thinking is not only a focus for faculty, but should also be emphasized by administration, student affairs staff, and across all departments and divisions throughout institutions of higher education. King and Kitchener (1994) provides strategies for student affairs staff to promote reflective thinking. By understanding student development of reflective judgment and providing activities and assignments that facilitate thinking in complex ways, faculty can greatly support student 
abilities to enhance reflective thinking in higher education. Appendix $\mathrm{C}$ provides a table that identifies some of the difficulties students experience during each stage, as well as examples of developmental assignments and support initiatives that instructors can employ to encourage development toward higher stages of reflective thinking.

Promoting reflective judgment is not only a good idea, it is encouraged by many associations and organizations affiliated with higher education (Association of American Colleges, 1991). According to the Association of American Colleges (1991),

[i]n the final analysis, the challenge of college, for students and faculty members alike, is empowering individuals to know that the world is far more complex than it first appears, and that they must make interpretative arguments and decisions - judgments that entail real consequences for which they must take responsibility and from which they may not flee by disclaiming expertise. (p. $16-17)$

The highest levels of support for the development of reflective thinking in students occur when all members of the institution support an initiative to improve reflective thinking. The most positive opportunities to promote reflective thinking are enhanced when the development of these type of skills are supported by the institutional mission, are built into the curriculum, and pervade all aspects of the college experience, regardless of the academic program or the preferred method of instructional delivery. The following eleven observations and suggestions are provided by King and Kitchener (2004) as ways to begin considering the development of reflective thinking:

- Show respect for students as people regardless of the developmental level(s) they may be exhibiting. 
- Understand that students differ in regard to their epistemic assumptions (assumptions about knowledge).

- Familiarize students with ill-structured problems within your own discipline or areas of expertise.

- Create multiple opportunities for students to examine different points of view on a topic reflectively.

- Create opportunities and provide encouragement for students to make judgments and to explain what they believe.

- Informally assess students' assumptions about knowledge and how beliefs should be justified.

- Acknowledge that students work within a developmental range of stages, and target expectations and goals accordingly.

- Provide both challenges and supports in interactions with students.

- Recognize that challenges and supports can be grounded emotionally as well as cognitively.

- Be cognizant of which skills are required for selected activities or assignments.

- Foster a climate that promotes thoughtful analysis of issues throughout the campus. (p. $230-255)$

\section{Research using the Reflective Judgment Model}

Since the introduction of the RJM, many researchers have used King and Kitchener's theory to investigate student development of reflective judgment in a variety of educational settings and encompassing multiple programs of study or educational endeavors to determine if student development in reflective judgment reaches appropriate stages. In a study of self- 
transcendence and psychosocial experiences of undergraduate and graduate students, Freeman (2004) found evidence of an increase in reflective judgment scores across education levels. Jackson (2008) showed how reflective judgment could be further supported by effective teachings styles and an accurate understanding of the learning styles present in the classroom. King and Shuford (1996) took a look at the effects of single term courses which can strengthen and teach new skills, and provide an avenue to support further development of reflective judgment stages. Ilacqua and Prescott (2003) illustrated how utilization of class assignments that focused on the complex nature of economic model supported development of reflective judgment. Each of these works examines the ways that reflective judgment may be gained, developed, or shaped in higher education. These studies demonstrate that the RJM was not only a relevant model when first designed, but is still necessary in the current landscape of higher education.

One of the most prominent and well-researched models of cognitive develop was first conducted by King and Kitchener which examined students in high school, undergraduate, graduate, and doctoral programs over a 10-year period (Pascarella \& Terenzini, 1991). The study found that scores were lower for participants who did not possess college degrees and the scores for every sample remained the same or improved over time for those participating in some sort of educational settings (King \& Kitchener, 1994). The study also showed that the greater the length of time between the testings, the greater the growth in reflective judgment. More recent studies have expanded the understanding of reflective judgment to show that "reflective thinking evolves slowly and steadily,...reflective thinking is associated with participation in education programs,[and improvement in reflective thinking] were consistently observed in studies of at least a year's duration" (King \& Kitchener, 2004, p. 14-15). An interesting conclusion that 
provides direction for this study shows that advancement in reflective judgment can be related to interactions one has with their environment (King \& Kitchener, 2004). Because of the differences in the person-environment interactions of students enrolled in traditional on-campus programs of study and students enrolled in online programs of study, it is important to compare stages of reflective judgment between students in online and traditional programs of study.

In a cross-sectional study completed by King and Shuford (1994) which reviewed 20 other studies that examined student acquisition and development of reflective judgment, the authors identified "that two-thirds of...freshmen reasoned between stages 3 and 4" (p.157), showing that first-year students, on average, represent characteristics of late pre-reflective to early quasi-reflective stages. From the samples gathered from seniors in these studies, minimal evidence of prereflective thinking was present; rather, seniors demonstrated characteristics of quasi-reflective thinking (King \& Shuford, 1994). In another study that compared the scores of freshmen and seniors, King (2000) identified statistically significant difference between the scores, "which suggests that important shifts in epistemological assumptions are occurring during the college years" (pg. 22). Since evolution through the RJM is shown to occur slowly over time, stages of reflective judgment will be compared in this study to see if students, who are enrolled in higher educational studies in business-related programs, have a statistically significant difference depending upon their class rank, e.g. junior, senior. This is supported by previous research that shows the development of reflective judgment increases during higher education, and emphasizes a significant relationship between a student's reflective judgment and his or her level of education (King, 2000; Friedman, 2004).

Students entering higher education have diverse backgrounds, learning experiences, and previous educational endeavors; therefore it would be erroneous to categorize all freshmen as 
pre-reflective thinkers. Rather faculty should be aware that these experiences may affect a student's stage of reflective judgment depending upon the subject being covered (Jackson, 2008). Friedman (2004) showed that "[e]xperiences such as participating in community service activities [and] student government ... not only enhance understanding of other perspectives, but also encourage self-transcendency, expansion of social radius, and acknowledgment of universal truths" (p. 303). This expands the view of reflective judgment to include "the effect of social, historical, and cultural experiences on the development of reflective judgment" (Friedman, 2004, p. 303). These experiences not only relate to reflective judgment, but also relate to the mission of many institutions of higher education in America "that includes some aspect of moral development, such as preparation for citizenship, character development, moral leadership and service to society" (Mayhew \& King, 2008, p. 18). In a 2009 study, Friend, Caruthers, and McCarther investigated the use of electronic journaling to support reflection and found that "the greatest resistance in self-reflection arose when issues of racial/ethnic diversity, social class, and sexual orientations were the subject of journal entries" (p. 11). Studies suggest that students who are able to interact with different cultures and individuals with different perspectives may postpone developing a decision until they have obtained a variety of evidence, suggesting a relationship between one's intercultural maturity and cognitive development (King \& Magolda, 2005). Additionally, development for an understanding and appreciation of diversity during educational endeavors requires an individual to exhibit reflective thinking skills (King \& Magolda, 1996).

As identified by King and Shuford (1996), "students who hold prereflective assumptions have great difficulty understanding cultural differences because they reason from an egocentric perspective that keeps them from acknowledging the basis for differing points of view" (p. 161), 
thus it is important to ensure that institutions of higher education support students' progress toward quasi-reflective judgment as it aligns with the institutional mission. This fact is further exemplified by Guthrie (1997) in that students' development in reflective thinking was likely to have a positive influence on the students' level of tolerance for diversity. Technological advancement and the globalization of education not only open new avenues and broaden opportunities for students to attend college, but provide occasions for institutions of higher education to support the learning differences that exist between cultures through effective online instruction (Wang, 2007; Parrish \& Linder-VanBerschot, 2010; Hodge, 2011). Furthermore, self-transcendence, or the "ability to transcend personalistic perspectives and embrace collective and universal concerns" (Friedman, 2004, p.298), becomes a necessary characteristic to develop in students of the $21^{\text {st }}$ century. The connection between cognitive development and social behavior is not new, but has been shown to have a developmental relationship and work in concert with one another when formulating a response and communicating with another individual (Flavell, 1977).

Ilacqua and Prescott (2003) “posit that an individual's progress through [the RJM] stages depends greatly upon that person's learning environment, which includes working with assignments designed to foster reflective thinking” (p. 369). When considering reflective judgment in higher education, online learning environments provide a unique difference in an individual's learning environment than one would experience in the traditional classroom (Hiltz $\&$ Turoff, 2005). Particularly, the environment could be said to differ greatly in terms of the technological tools employed to deliver instruction at today's institutions of higher education. Online delivery modes now allow students to attend class, study, and complete classroom requirements anytime and anywhere through synchronous and asynchronous delivery options. 
The physical environments in which students may now interact occur in their own bedroom, coffee shops, or the library on or off campus.

Support for the promotion of reflective judgment is provided by McLoughlin who "encouraged educators to provide personal and group online workspaces that encourage both private reflection and cooperative support" (as cited in Smith \& Ayers, 2006 p. 409). In a 2010 study of online versus traditional instruction, Angiello shows further support for a focus on enhancing reflection in online instruction by encouraging students to reflect on their learning and the content covered in the class. The opportunity to reflect during these educational and life experiences, as well as solve complex problems, supports students ability to solve such problems in the future (Seeleman, Suurmond, \& Stronks, 2009).

Many methods employed to initiate discussion in online classes between the instructor and students, as well as among students, allow participants to think about what they wish to say prior to delivery. These systems also provide students with the opportunity to review their own words for accuracy before viewed by the instructor or classmates. As identified by Jahnke (2010), some students expressed that this manner of written communication required more reflection because they "didn't want to write in a way that wasn't a reflection of [their] personality" (p. 33). Showing that "[t]he importance students place on reflection as a key intellectual process afforded by an online forum is very strong” (Jahnke, 2010, p. 32). Unfortunately, students with insufficient written communication skills are more likely to face challenges in this format. As stated by Ciges (2001), students who have diminished reading and writing abilities will function at lower levels in classroom settings that accentuate reading and writing, but "the opportunity for reflection that is created by computer-mediated communication contains educational value that should not be ignored" (p. 144). 
Previous research has examined ways that reflective judgment can be introduced and developed in online education, but to date, published research that compares reflective judgment development between online programs of study in business-related fields with traditional programs of study is lacking. Most research in this area has provided ways for instructors to facilitate reflective thinking in an online environment, and offered implications for further research in the vastly growing arena of technology-mediated education; but additional research is needed to analyze the stages of reflective judgment, and to determine if appropriate stages of reflective judgment are formed in graduates. "It is possible that psychosocial experiences like leaving home, going away to college, meeting new people, becoming employed, and experiencing a variety of positive and painful experiences enhance autonomy that allows an individual to become more reflective in embracing and resolving life's dilemma's" (Friedman, 2004, p. 302). If this is the case, differences may exist for online students who do not leave home for college or participate in the traditional "college experience." Friedman's study reinforces King and Kitchener's finding that student development is affected through the personenvironment interaction, and adds a noteworthy implication to this study.

\section{Online Education}

Oftentimes distance education and online education are grouped together in discussions on technology and its relationship to delivering curriculum, yet they are distinctly different. Distance education is best defined by Keegan (1995) as a learning environment that does not require a student to learn at "a fixed place, at a fixed time, to meet a fixed person, in order to be trained or education (p. 7). Learning that occurs outside of the classroom has been studied extensively and researched by many scholars and organizations. In a study of online education, Allen and Seaman (2007) discuss how focusing on improving access for students, especially 
among non-traditional students are supporting the growth of online education. Ciges (2001) discusses additional benefits of online education and illustrates how increasing access to education can enhance the opportunity to share experiences in diverse settings. Additional arguments for the expansion of online coursework include providing a flexible schedule that enables students to integrate education with the demands of employment and family duties, allowing the instructor to be available to all students, and reducing the strain on the institution's infrastructure by minimizing the growth or duplication of administrative activities (Hiltz \& Turoff, 2005; Allen \& Seaman, 2010; Picciano, Seaman, \& Allen, 2010). Other studies support the latter point and argue that online learning provides a way to stay competitive in the education marketplace (Hiltz \& Turoff, 2005).

\section{Online growth}

In Evaluation of Evidence-based Practices in Online Learning: A Meta-Analysis and Review of Online Learning Studies (2010), a study released by the U.S. Department of Education, online learning was compared to traditional learning and the study found that "students in online conditions performed modestly better, on average, than those learning the same material through traditional face-to-face instruction." (p. xiv). Whatever the impetus to begin or expand online coursework, delivering education in an online format at institutions of higher education across America is growing rapidly with anticipated enrollment to exceed 22 million by 2014 (Nagel, 2009). In fact, many institutions have integrated online learning into their strategic plans (Picciano, 2006; Picciano, Seaman, \& Allen, 2010). The challenge that now exists is addressing the gap between the institutional objectives for online learning and the level of commitment by faculty to support these objectives (Seaman, 2009). As online education 
reaches more students, many colleges and universities look toward technology "as the golden token of providing access" (Rogers et al., 2007, p. 198) to all students in higher education.

Business-related education curriculum saw significant increases in online coursework and degree programs in the early 2000s (Robles, 2011). Since this time, many institutions have taken advantage of new technologies to deliver curriculum by offering a selection of courses online, such as Drexel University's Bennett S. LeBow College of Business, which delivers a variety of online coursework in business, management, and marketing (www.lebow.drexel.edu). Institutions such as the University of Florida offering a Bachelor of Science in Business Administration have chosen to develop degree completion programs online which allow students to take traditional coursework during the first two years of study and then register during the final two years in program-specific online coursework (www.warrington.ufl.edu). Still others, like Crookston's Bachelor of Science in Business Management at the University of Minnesota, offer a baccalaureate program of study completely online (www1.crk.umn.edu). Obviously, online courses and programs are offered at a variety of institutions in a variety of forms. Allen and Seaman (2010) state that online coursework is expected to expand further in future years with sixty-three percent of all surveyed institutions emphasizing "online learning [as] a critical part of their institution's long term strategy" (p. 2). Online education is not only a growing approach emphasized by the institutions themselves; it is also desired by college students wishing to supplement or replace the traditional learning environment. These factors have supported enrollment growth at a pace that vastly surpasses the total student population in higher education (Allen \& Seaman, 2010).

Many policymakers who monitor the higher education landscape consider "that if online instruction is no worse than traditional instruction in terms of student outcomes, then online 
education initiatives could be justified on the basis of cost efficiency or the need to provide access to leaners in settings where face-to-face instruction is not feasible" (United States Department of Education, 2010, p. xi). If Thorseth (2008) is correct in that advances of technology in education provide resolutions to the difficulties recognized by Dewey and other philosophers before his time, then online learning should also be equally effective as traditional learning in supporting the development of reflective judgment. To this end, it is possible that online learning opens avenues for students to control their own learning, thus requiring students to anticipate and develop responses to ill-structured problems in course assignments (Artino \& Stephens, 2006).

Considering the momentous growth in trends for online coursework and online programs in higher education, many are concerned about the ways student learning will be supported for those who enroll in this mode of instruction (Rakes \& Dunn, 2010). Recent studies have shown that students enrolled in online courses of study can be as successful as those enrolled in traditional learning environments, regardless of their learning style or preference (Aragon, Johnson, \& Shaik, 2001, 2002). Much attention has been paid to how students learn, or what learning styles they prefer in both methods of delivery. While it is important to understand the various methods employed by faculty to reach all learners in a learner-centered environment, it is just as significant in learner-centered education to understand cognitive development and reflective judgment, particularly in online classes, since students must exhibit information literacy abilities by simply navigating through online instruction (Jackson, 2008). In a study of undergraduate students completed by Whitmire (2004), the author examined the relationship between epistemological beliefs, reflective judgment, and information-seeking behavior. Results 
of the research identified a relationship between epistemological beliefs and information-seeking behavior, and between reflective judgment and information-seeking behavior.

\section{Instructional techniques employed online}

“All people develop universal basic cognitive abilities, but the specific ways in which they are used will depend on the social and educational environments in which other human beings act as the main learning mediators" (Ciges, 2001, p. 137). New developments such as web blogs and message boards provide methods that encourage and facilitate these environments, but in different ways. In new virtual learning environments, social presence is more about the ways students present themselves as a "real" person so their personality comes through and the connection that students have with one another in this environment (Wang, 2007; Diaz, Swan, Ice, \& Kupczynski, 2010). As identified by Smith and Ayers (2006) these experiences go beyond the traditional learning environment to include "'virtual communities', where learners [who] are distributed geographically communicate with each other and with their instructions electronically" (p. 410) in an online learning environment. Rakes and Dunn (2010) show that this form of interaction may take place through the deployment of interactive technologies like chat rooms and discussion boards. In fact, proper utilization of technology available to faculty will provide an effective setting for reflective thinking (Johnson, 2011). And, in a study conducted by Jahnke (2010) that interviewed students regarding discussion forum format in an online course, students perceived "the opportunity to access other opinions and information not residing within the classroom or the teacher . . . as the most beneficial aspect" (p. 29) of the online learning environment. The effective use of the various tools that exist in an online learning environment may greatly support student learning and address much of the discontent that surrounds online learning in academic discourse (Miller \& Mazur, 2009). 
Therefore teachers in this learning environment must ensure that instruction is designed to take advantage of the ways that technology can enhance learning.

According to Ciges (2001), “[o]ne of the key aspects of online education is the teacher's capacity to produce positive interaction sequences with and among students" (p. 137). As advances in technology continue to improve the tools available in education, this interaction can now be supported in an online environment without students physically occupying a seat in a classroom. While many online instructional techniques mirror attempts of the traditional classroom to facilitate reflective judgment, simply adding tools such as blogs, discussion forums, chat rooms, and wikis is not enough. Faculty must be certain to evaluate and assess the tool's effectiveness in supporting the experiences necessary to enhance development of reflective judgment (Jahnke, 2010). Faculty must also establish requirements for communication in an online learning environment that promotes and enhances reflective judgment (Thorseth, 2008).

Similar to the utilization of portfolios in traditional learning environments, ePortfolios have become a new tool employed online that provide opportunities for students to evaluate and reflect on their learning, thus promoting metacognition (Huba \& Freed, 2000; Suskie, 2004; Bollinger \& Shepherd, 2010). Bollinger and Shepherd (2010) used a questionnaire to obtain student perceptions of ePortfolios to show that this activity "positively impacted some students' perception of communication, connectedness, and learning” (p. 295). In a 2004 study by Ellis, Calvo, Levy, and Tan, the authors identified that online discussions provided students with the opportunity to reflect on comments from others in order to support their own thinking; however, such opportunities were not provided in face-to-face discussions. In an online environment, students are not limited to the constraints of a typical class period where only a limited amount of time is available to receive communication from a few students (Picciano, 2006). All students 
are now able to participate in the discussion and are able to enjoy added flexibility in terms of time and location to participate in the communication (Zeliff, 2011). As a way to enhance reflection in online environments, faculty must be sure to provide students with the opportunity to have greater control of their interactions using online tools, and extend occasions to work individually to become skilled at reviewing and reflecting on their comprehension (Angiello, 2010; Hite, 2011). Employing the variety of tools made available to faculty through advancement in technologies "make open and distance learning a fully viable alternative to traditional education, creating a natural environment for the development of effective virtual learning communities" (Parrish \& Linder-VanBerschot, 2010, p.2).

\section{Conflicting perspectives}

When surveying faculty about the effectiveness of both online and traditional education, you will find supporters and detractors for each method of instruction. In an annual study that monitors online learning at institutions of higher education, Allen and Seaman (2010) report that sixty-six percent of respondents believe that online education is as effective or more effective than traditional instruction in meeting established learning objectives; a percentage that has continued to increase since the first report in 2003. Recent studies have also shown that instructors perceive online learning to provide a more meaningful learning experience than students generally perceive; students conversely, perceive the experiences that occur in a traditional learning environment to be more meaningful than those of an online program (Lofstrom \& Nevgi, 2006; Dobbs, Waid, \& Carmen, 133). However, when asked about the factor that lead a student to select a program of study in a traditional learning environment, students emphasized that accreditation was a major area of importance (Dobbs, Waid, \& Carmen, 2009). 
Although positive findings and recommendations emanate from previous reports, many other researchers and faculty have concerns about the effectiveness of online instruction and feel that this form of education limits the loyalty students develop by attending campus, and "threatens to commercialize education, isolate students and faculty, and may reduce standards or even devalue university degrees" (Aragon et al., 2001, p. 5; Dobbs et al., 2009; Picciano, Seaman, \& Allen, 2010). This is just another facet that contributes to the negative perception of online learning and its role in higher education. In fact, some faculty not only voice concerns that online learning is inferior to traditional learning, but that instruction that occurs face-to-face is "the only acceptable way to teaching and learning" (Angiello, 2010, p. 56). Some common barriers have been cited when addressing adoption and expansion of online courses and programs at institutions of higher education. These include the lack of discipline exhibited among students enrolled in these courses, the lack of faculty acceptance of online delivery as an effective method of education, the added costs necessary to suitably develop, maintain, and support the online curriculum, as well as the strain placed on the entire technological infrastructure at these institutions (Allen \& Seaman, 2007; Picciano, Seaman, \& Allen, 2010). In a study conducted by Dobbs et al (2009), the authors found that "both those who had taken online courses and those who had not ... agreed that students learn more in traditional courses while disagreeing that students learn more online (p. 21). Additional results from this study also show that students felt that traditional learning provides more organization than online courses, a view that differed from faculty who felt that online courses are more highly structured (Dobbs et al., 2009). From this research, faculty replies were, overall, negative toward the delivery of online courses and programs, and included statements about online learning such as, "[i]t will peak and plateau as more and more employers realize what they get with students who only learn 
through a computer - people who lack imagination and the ability to interact with other people" (139). This view that online education reduces standards is expressed by Ciges (2001) who states that the virtualization of education may "fail to meet basic educational requirements since they are designed from a technological point of view instead of taking educational needs as a starting point" (p. 146).

Previous studies "indicate that there are problems with both the quantity and quality of online interactions that can undermine inquiry goals" (van Aalst, 2006, p. 279), and that technology may worsen instead of resolve questions of impartiality in education (Smith \& Ayers, 2006). In another study completed by Dobbs et al (2009), the authors illustrate that the convenience associated with distance education may draw students to enroll, but the quality of the learning environment is the key to keeping students engaged and promoting success. As shown by the various perceptions and studies completed on distance education, these tools offer both potential opportunities and difficulty for institutions of higher education (Smith \& Ayers, 2006).

While specific tools have been implemented to enhance communication in online learning environments, students do not communicate online with classmates in a manner equivalent to the traditional learning environment, wherein visual information is obtained. The lack of physical presence and visual cues of another individual when communicating online has a greater effect on perception and feelings of isolation than one might realize (Friend et al., 2009; Liu, Magjuka, Bonk, \& Lee, 2009). Since most online environments lack the visual component, students must develop their own interpretation of how others with whom they are communicating may appear. The virtualized communication can support delivering information; however, Hyton (2007) found that the exchange that occurred in online environments "reflected 
one-way interaction, rather than ongoing exchange of ideas" (p. 65). In fact, as is the case in a traditional learning environment, relevant interactions among students and the instructors are a necessity to deliver successful online learning environments (Orellana, 2009). Ward (2010) emphasizes that if communication competencies are desired outcomes of students enrolled in the program, the traditional face-to-face learning environment is a fundamental need in the learning environment.

Lombardi and McCahill state that the experiences gained by students in an online learning environment "lack the social dimension that characterizes learning in the real world" (as cited by Jahnke, 2010, p. 30). In a study that considered asynchronous discussions, BiesenbachLucas found "online discussions to be beneficial for social interaction and learning" (as cited by Uzuner, 2009, p. 6), but the discussions that took place did not exhibit the thinking necessary to produce critical assessment and synthesis. In many cases, much of the technology utilized in online learning may produce even greater cultural challenges, and because an individual's culture influences their perceptions about the learning environment, online learning poses additional challenges in terms of cultural diversity (Rogers et al., 2004; Wang, 2007; Tan, Nabb, Aagard, \& Kim, 2010). In fact, a survey of online educators identified the failure to recognize cultural changes as the greatest obstacle to successful online education (Kipta \& Berge, 2006). Ways to bridge this disconnect must be developed and, currently, this attempt is being made in online learning. Considering the concerns surrounding the lack of social dimension and interactions, Rogers et al (2007) emphasize that institutions of higher education should conduct "more critical interrogation[s] of the political and cultural implications of the new technologies in education" (p. 208) in order to ensure students leave college with the skills necessary to be a productive member of society. Further support for enhancing the social dimension in an online 
learning environment is evidenced by Diaz et al (2010), where students indicated that the social dimension is an important factor in online learning.

Other concerns have been identified, such as the equality of learning outcomes between each mode, the value of relationship between faculty and student, the quality of communication, and the depth of reasoning available to students who enroll in online classes, as well as discouragement due to group differences, social isolation, excessive amounts of information that is available on the web, sense of trust, and absence of verbal cues. (Ciges, 2001; Hylton, 2007; Jahnke, 2010; Bollinger \& Shepherd, 2010; Rakes \& Dunn, 2010; Morgan, Cameron, \& Williams, 2009).

In spite of some negative views associated with online learning, Hiltz and Turoff (2005) states that online education provides valuable "benefits to the students, the organizations, and to the society" (p. 62). "Siemens (2008) reports that a growing disconnect in the tools and methods of classroom activity and those of youth culture and larger society is evident" (Jahnke, 2010, p. 34). This disconnect can be exacerbated due to the limited research that exists to help explain how cultural differences among students affect online learning (Tan, Nabb, Aagard \& Kim, 2010). In a study of students enrolled in business programs completed by Smith and Ayers (2006), the authors showed that a "relationship exists between an individual's cultural background and his or her overall attitude toward distance learning” (p. 407).

Additionally, some academic leaders do not share the same negative views about the acceptance of online degrees by the workforce (Allen \& Seaman, 2007, 2010). Many employers find online courses to be beneficial for professional development for the incumbent workforce, which allows employees to complete coursework without taking time off. In fact, employers often require employees to keep up to date or "develop specialized skills that match the needs of 
a rapidly changing world [and] demand access to proper educational opportunities" (Parrish \& Linder-VanBerschot, 2010, p. 2) that are provided by institutions of higher education through online courses. The support for online education is further illustrated by students who, in many cases, hold a position of employment or are recently returning to education after working for many years. Oftentimes students have families which compete for their spare time, leaving many students with limited amounts of time to connect with learning experiences at the level that faculty favor (Hiltz, 2005; Jackson, 2008).

In a comprehensive meta-analysis, Zhao, Lei, Yan, Lai, and Tan (2005) illustrate that in spite of the differences that exist in a class that uses technology to deliver education, it is education nonetheless and it should not be discounted. Despite the differences, it is important to investigate reflective judgment in this environment which is central to the development of knowledge and concerned with the manifestation of individual assumption, "the process whereby they establish a fact, put two or more of them together, come to conclusions as to their meaning, and perhaps even soar with some leap of imagination to a thought that has never been thought before" (King, 1992, p. 1). The question that remains is, do students enrolled in online degrees in business-related fields exhibit similar stages of reflective judgment as those in traditional learning environments?

As shown earlier, faculty have competing opinions on the capability of online classes to adequately address learning objectives set forth for a course. Since online courses and programs continue to expand, there must be demand from students for this form of education, as well as from motivated faculty to expand teaching in this mode, explaining the impetus of administration to allow such expansion to occur. In a study designed to obtain student perceptions, Dobbs et al (2009) found that eighty-one percent of students with previous experience in online courses 
stated that they would take more online courses in the future. Additionally, only three percent stated that they chose an online course because the traditional section was full or only offered online, showing that flexibility, family responsibilities, and other factors were more likely to persuade students to select online courses (Dobbs et al., 2009). Students identified the driving factor to select online courses was the degree of conformity with their busy schedules, as online coursework provides flexibility to decide when to study and complete assignments (Dobbs et at, 2009).

In Dobbs et al (2009) study, research showed that each form of learning provides avenues that students value since "nearly three fourths of those in the online program reported they preferred online courses, while about three fourths of those in the on-campus program reported that they preferred traditional classes" (p. 16). Like the various perceptions of faculty, the study showed similar contradictory views from students. Continuing with Dobbs' et al study, students with previous experience with online coursework reported that they did not agree that the quality of online courses were lesser than those of traditional courses, while those without previous online experiences felt that traditional learning environments were superior.

\section{Conclusion}

Much of the history of higher education has evolved to develop as "a highly regulated industry... and the introduction of the Web is beginning to turn it into a deregulated industry" (Hiltz \& Turoff, 2005, p. 63). Many recent articles show that diverse groups of stakeholders have begun weighing in on this topic: faculty, administrators, students, employers, parents, and state and federal governments. Many of the competing views of online education have prompted faculty teaching in this format to begin research that has provided educators with an abundance of data and analysis to understand ways to improve student learning in this setting (Diaz, 2011). 
Unfortunately, research-based strategies for online education are only being developed recently, and many faculty who instruct in this format are still honing their skills. In fact, many institutions have begun to employ distance and online education without first researching how the methods used in these formats will affect student perceptions (O’Malley \& McCraw, 1999). Institutions of higher education are receiving increased oversight in a time of new challenges from accreditors, the government, and the public as a whole, and are faced with a growing and diverse population who is often ill-prepared to enter college. Students are entering an environment not previously experienced; in fact, many are first time college students in the family and have no clear vision as what to expect. Yet, the institution must educate the student and send them out in the world to be a productive member of society. Students are expected to demonstrate twenty-first century skills of flexibility, adaptability, and comprehension of a diversity of information; skills that are enhanced and defined by reflective judgment. 


\section{Chapter III - METHODOLOGY}

Introduction

The purpose of this study was to identify and compare stages of reflective judgment for students enrolled in traditional academic programs with students enrolled in online programs of study in the business field. This study builds upon previous research utilizing King and Kitchener's Reflective Judgment Model (RJM) by analyzing a comparison of reflective judgment between traditional and online academic programs. The stages of reflective judgment were assessed using the Reasoning about Current Issues (RCI) questionnaire and compared scores on the RJM. The RCI instrument is an objectively scored assessment tool devised as one of the ways to measure reflective judgment (King \& Kitchener, 2004). An average score for each group was calculated and the difference between the two groups is explored. When conducting the study with students using the RCI instrument, it is necessary to gather minimal demographic data to gain a greater insight of the students who are participating in the study, and to allow for a comparison between online and traditional modes of delivery being selected by participants.

In the following sections the procedures used for research design are described, including survey research design, research question, description of the population and the sample, research method chosen, data collection procedures employed, analysis of data, and the limitations of the study. Additionally, a summary of ethics and the researcher's background are provided.

\section{Research Design}

The research employed quantitative research methods to obtain information about the average level and stage of reflective judgment present with each group and attain an understanding of the differences in the RCI mean scores between groups. Quantitative research 
obtains data in the form of numerical information, and the variable measured and the procedures followed to collect and analyze data are predetermined (Meadows, 2003). This form of research is effective in calculating a collection of group characteristics and averages. Quantitative studies allow for relations between psychological and social phenomena to be "investigated in terms of generalizable causal effects, which in turn allow for prediction" (Gelo, Braakmann \& Benetka, 2008, p. 268).

The model of reflective judgment provides two ways to assess levels of reflective thinking - an established interview protocol for qualitative review using the Reflective Judgment Interview (RJI) and a survey method for a quantitative review employing the RCI. The chosen methodology of data collection to be employed in this study is the RCI instrument. Training to utilize the RJI and become certified to employ the instrument is no longer provided. Additionally, the RCI enables making a comparison of the average level and stage of reflective judgment present between groups.

\section{Research Question}

What are the differences among reflective judgment scores of students enrolled in business-related programs due to factors of class rank and program delivery format?

\section{Independent variables}

The independent variables in this study are 1) class rank, 2) age group, and 3) gender. The independent variables were captured through subject coding to identify the student rank. Age group and gender were captured for each participant when completing all necessary demographic information on the RCI. Note, however, that only rank was predetermined to be an independent variable of a-priori null hypothesis testing. The definitions of the independent variables are: 
- The independent variable of class rank has two levels. The two levels are junior versus senior status in the academic program.

- The independent variable of age group has two levels. The two levels are traditional age versus non-traditional age.

- The independent variable of gender has two levels. The two levels are male versus female.

\section{Dependent variable}

In this study the dependent variable is the reflective judgment score as calculated by the RCI. The mean score is a weighted ranking that is determined based on a student's response to a set of established questions of ill-structured problems. To summarize, the dependent score is:

- Reflective judgment score calculated by the Reasoning about Critical Issues questionnaire.

\section{Statistical Model}

While the intent of the study was to use a two-way ANOVA to explore comparisons in the research question, a low response rate from students enrolled in online programs of study does not allow the researcher to obtain a sample size large enough to fully analyze students enrolled in online programs of study based on the requirements of analysis of the RCI assessment instrument for reflective judgment. As such, and with approval of the dissertation committee, a $t$-test was used to compare the differences between the mean scores of juniors to the mean scores of seniors to determine if a statically significant difference between the two groups exist.

Additional data captured through the collection of respondents' demographics allowed for further analysis. A $t$-test was used to compare the differences between mean scores of 
traditional aged students to the mean scores of non-traditional aged students to determine whether the difference is statistically significant between the two groups. As revealed in research, reflective judgment is shown to increase when students participate in educational study and experiences in college (King \& Kitchener, 1994, 2004). Additionally, reflective judgment is shown to increase with age, thus this further examination based on age-group is important for analysis in the study (King \& Kitchener, 1994). And finally, a third $t$-test was used to compare the differences between the mean scores based on gender and to see if the difference between males and females is statistically significant.

This study used different respondents to examine samples of the population, thus employing an independent sample $t$-test. This statistical technique may be used when comparing two different groups (Field, 2005). To minimize the effect for systematic variation, random samples were drawn from seven institutions of higher education from four separate states. Assumptions of the $t$-test are considered in this study: 1) population utilized in the study are normally distributed, 2) measurements are made at the interval level, 3) homogeneity of variance, and 4) scores about from the study are from different participants (Field, 2005).

\section{Null hypothesis}

There is no significant difference at an alpha 0.05 level, for the independent variable (class rank, age group, or gender) on the dependent variable (reflective judgment score). The null hypothesis states that the mean scores of all groups would be equal. Expressed mathematically:

$$
\mu_{1}=\mu_{2} \text { and } \mu_{1}-\mu_{2}=0
$$


Fully expressed, the null hypothesis states that the calculated mean of the independent variable population is equal and the difference between the independent samples will equal zero. Expressed mathematically:

Independent variable $\mathrm{A}: \mu$ class rank (junior) $=\mu$ class rank (senior) and $\mu$ class rank (junior) -

$\mu$ class rank (senior) $=0$

Independent variable $B: \mu$ age group (traditional) $=\mu$ age group (non-traditional) and $\mu$ age group

(traditional) $-\mu$ age group (non-traditional) $=0$

Independent variable $C: \mu$ gender (male) $=\mu$ gender (female) and $\mu$ gender (male) $-\mu$ gender $($ female $)=0$

The independent variable A examines whether or not there is a significant difference in RCI scores when comparing junior and senior students. In the event there is a statistically significant difference it would suggest the differences in RCI scores taken from students in business-related programs differ depending on whether examining the results of juniors or seniors. The independent variable B examines whether or not there is a significant difference in RCI scores when comparing traditional and non-traditional aged students. In the event there is a statistically significant difference it would suggest the differences in RCI scores taken from students in business-related programs differ depending on whether examining the results of traditional or non-traditional students. The independent variable $\mathrm{C}$ examines whether or not there is a significant difference in RCI scores when comparing male and female students. In the event there is a statistically significant difference it would suggest the differences in RCI scores taken from students in business-related programs differ depending on whether examining the results of males or females. 


\section{Instrumentation}

This study used the RCI to gather information. The tool is available to researchers through a collaborative arrangement with the University of Michigan. The instrument has been used by many studies and exhibits overall a .839 alpha coefficient. For each main effect to occur, thirty respondents are necessary. Ideally a sample size of 120 with thirty respondents in each cell was sought for this study.

The tool takes thirty minutes to utilize, on average. Respondents are asked to respond to three ill-structured problems by selecting from a range of responses. The respondent will select the response that most closely aligns with their reasoning. Respondents are then asked to rank the order of the responses from how closely they related to their thinking. Rather than making interpretations about individual responses, the instrument is designed for the researcher to make inferences about groups of individuals.

The RCI is comprised of four questions: the first question uses a likert scale to obtain the respondent's opinion of one of three topics; work force, alcoholism, or immigration. Next respondents must write a response to describe how they feel it is likely that differing opinions exist among professionals in the field. Then respondents use a likert scale to indicate how similar their responses are to a set of predesigned statements regarding the topic. Lastly, respondents rank the top three of ten questions in the order of how closely related they are to their own opinions of the topic. The RCI questionnaire is delivered online and designed to allow respondents to select from a list of statements that best describes how they view a particular dilemma. The instrument must be delivered in a controlled environment where respondents' distractions are limited. Employing a weighted system of ranking responses, the instrument allows for scores from stages two to seven to be obtained as an estimate of the stage selected by 
respondents as most similar to their thinking. A calculation estimates an average for the sample group.

Although the tool is only utilized to compare groups, individual data is provided in the event the researcher prefers to compare the scores between other subgroups or potentially review pre and post test scores (reflectivejudgment.org). Information provided to the researcher includes demographic data (gender, birth date, race, ethnicity, and citizenship), individual dilemma ratings, and overall RCI rating. To ensure confidentiality, respondents' names were not recorded, but are identified by a number. The data self-reported responses from participates are gathered to determine the class rank and program delivery method.

The tool is copyrighted, so in order to utilize the RCI the researcher had to first request approval and received permission that verifies the research is a proper setting to employ the RCI tool. Upon receiving approval, the researcher was identified as a project administrator and provided with an unique password to ensure data integrity (www.reflectivejudgment.org). A large database exists with the tool, which provides an advantage over developing a new tool to be employed in the study. As part of the approval process, all researchers who utilize the RCI must submit responses, interpretations, and results of their studies so that future comparisons can be obtained. Once all questionnaires had been completed, the researcher was provided with a summary of the report and a Cronbach's alpha score.

\section{Matrix of Analysis}

Table 1 Matrix of Analysis represents the data source employed for the study and the proposed analysis for answering the research question. The first column of the table depicts the independent variables and dependent variable of the study. The second column shows the data 
source used to obtain the reflective judgment score, and the third column indicates an independent sample $t$-test method for the analysis.

Table 1

Matrix of Analysis

\begin{tabular}{|c|c|c|}
\hline Independent Variable & Data Source & Proposed Analysis \\
\hline Class rank & Reasoning about Critical & Independent Sample $t$-test \\
& Issues questionnaire & \\
\hline Age group & Reasoning about Critical & Independent Sample $t$-test \\
& Issues questionnaire & \\
\hline Gender & Reasoning about Critical & Independent Sample $t$-test \\
\hline Dependent Variable & Issues questionnaire & \\
\hline Reflective judgment score & Reasoning about Critical & Independent Sample $t$-test \\
& Issues questionnaire & \multicolumn{1}{|c|}{} \\
\hline
\end{tabular}

Selection of Population and Sample

The participants in this study were drawn from students in their junior year and students in their senior year currently enrolled in undergraduate programs of study from four-year accredited institutions. Participants were selected from colleges and universities in the United States of America that have both online and traditional baccalaureate business-related programs of study and are accredited by the Council for Higher Education Accreditation (CHEA).

There are several reasons for the selection of students enrolled in business-related majors within undergraduate programs. Typically, business-related programs utilize activities that are 
cited to promote reflective thinking, and students enrolled in business-related programs are likely required to use problem-solving skills regularly. Additionally, these students often experience a diverse population, face unstructured problems in the workplace, and will be required to anticipate future changes in the business environment (Wolcott \& Lynch, 1997). Businessrelated programs are also popular programs chosen to be delivered online by colleges and universities. Because of their popularity, there is a greater likelihood to select an institution with large enough enrollments in both program delivery formats to support the sample necessary for this study.

Student responses are anonymous. Demographic data was gathered to describe the student body and identify any trends that may exist in the research findings.

\section{Institutional Review Board}

The researcher applied to West Virginia University Institutional Review Board to receive human subject's clearance and ensure for the protection of human subjects. Upon IRB approval, the researcher communicated to participating institutions and provided a brief explanation of the study, procedures used to collect data, benefits afforded participating institutions, and information regarding confidentiality to receive written permission to conduct the study.

Data Collection and Analysis Procedure

1. Identified a independent sample $t$-test as the chosen test for this study;

2. Set significant levels at $a>0.05$;

3. Administered the Reasoning about Critical Issues questionnaire to the sample;

4. Formatted the data into SPSS and developed tables to illustrate the data;

5. Organized the data, including demographic information, into data sets;

6. Removed any information to ensure anonymity during the data coding process; 
7. Coded data based on demographic characteristics;

A. Academic Standing: Junior or Senior

B. Highest Education Level: High School, Attended College, Associate Degree, Bachelor Degree, or Masters Degree

C. Gender: Male or Female

D. Age Group: Traditional (18 - 24 years of age) or Non-traditional (25 years of age or older)

E. Race: White/Caucasian, Black/African American, or Asian/Pacific Islander

F. Ethnicity: Hispanic or Non-Hispanic

G. Citizenship: US Citizen or Non-US Citizen

H. Academic Delivery Format: Online or Face-to-Face

8. Utilized SPSS to perform the $t$-test;

9. Identified if effects of the independent variables are significant;

10. Presented findings, conclusions, and recommendations.

$$
\text { Limitations of the Study }
$$

The following limitations are identified to ensure adequate utilization of the reported data.

1. Since the self-reported data collection method is utilized, misunderstanding of the question or simply a poor memory can contribute to inaccuracies.

2. As this research utilized a sample to represent the target population, generalization of the results that will represent the target population should be conducted with caution. 
3. The researcher anticipates the findings of the study will have strong implications for students enrolled at the institution being studied; he may not have the ability to generalize to all postsecondary institutions across the nation.

4. Data is collected from students enrolled in business-related programs during the fall 2011, spring 2012, and summer 2012 semesters. As a result, the participants may not be representative of the entire student body at the institution, thus generalization should be done conservatively.

5. Ideally this study would focus on students enrolled in a business administration program, however to make this a more viable study institutions selected are determined by the presence of business-related programs, i.e. management, administration, human resources, finance, etc.

6. While all variables cannot be controlled in this study, the ideal institutions selected had a large enrollment, diverse student body, progressive teaching methods to enhance reflective judgment, and have large four-year with a majority of undergraduate Carnegie classification.

7. The researcher could not anticipate the response rate of the participants, thus results may be affected by biased responses.

8. The sample size preferred for this study is ideally gathered from one institution, but to ensure an adequate sample is obtained the researcher employed data from more than one institution resulting in slight differences in the contexts between institutions.

Institutional and Participant Cooperation Strategy

The following steps were followed to secure institutional approval, and institutional and participant cooperation. 
1. The researcher began investigating institutions with online and traditional programs of study and sent an email to institutions to garner the level of interest in participating in the study.

2. The researcher completed all training required of the CITI Training Program by the West Virginia University Institutional Review Board for the Protection of Human Subjects (IRB).

3. The researcher applied for exempt review by the IRB at WVU for studies involved in human subject research. IRB approval was received (See Appendix D).

4. After IRB approval, a follow-up email was sent to institutions previously contacted, and an invitation email was sent to additional institutions to participate in the study.

5. In many situations, the researcher was required to apply for review board approval at participating institutions to ensure adherence to institutional practices.

6. After receiving permission by the institutions to participate, the researcher sought out a faculty and/or administrative sponsor at each institution to identify students within the desired sample for the study. To ensure anonymity, the institutions did not share student names or identifiers, and the researcher did not share individual reflective judgment scores.

7. Upon receiving low response rates, the researcher submitted an amendment to IRB at WVU to include additional institutions. IRB approval for the amendment was received (See Appendix E).

8. The researcher then sent a participation letter to the sponsor at participating institutions to deliver to students. This letter clearly identified that student participation was voluntary and would not affect their standing at the institution. 
Contact information for any questions regarding the research project was also provided (See Appendix F).

\section{Researcher's Background}

The researcher earned a Bachelor of Science degree in business administration with a minor in computer and information science from Shepherd University. The researcher also earned a Master of Business Administration from Frostburg State University. Currently, the researcher is enrolled at West Virginia University as a doctoral candidate in educational leadership studies with a minor in instructional design and technology. The researcher is also an Associate Vice President of the School of Business and Information Technology at Blue Ridge Community and Technical College and has seven years of experience as a faculty member teaching both live and online in the fields of business and management. The researcher's role as an administrator requires analysis of student success, both academically and socially, in programs that deliver coursework in live and online formats.

\section{Summary}

This chapter discussed the research design applied to the research question for this study. Relevant information was proved about the RCI questionnaire, limitations identified for the study, description of the population, data collection procedure, and statistical method used for analysis. The researcher will conduct this study during fall 2011, spring 2012, and summer 2012 semesters. 


\section{Chapter IV - FINDINGS}

Introduction

This dissertation study surveyed junior and senior students enrolled in business-related programs of study at seven institutions of higher education in the United States, accredited by the Council for Higher Education, and examined reflective judgment scores of respondents to better understand group comparisons. Reflective judgment scores were determined for juniors and seniors enrolled in business-related programs of study in face-to-face and online formats of delivery utilizing the Reasoning about Critical Issues (RCI) assessment to provide a quantifiable score for groups. The RCI instrumentation can provide an understanding of the cognitive development of reflective judgment that occurs in adolescents and adults (King \& Kitchener, 1994). The differences in reflective judgment were recognized between juniors and seniors, and RCI scores of those enrolled in online and face-to-face formats were gathered. But because of a low response rate of students enrolled in online programs of study the construct of reflective judgment is reviewed and discussed in relation to how it may manifest in the online learning environment since it is unable to be analyzed utilizing the RCI instrumentation to calculate reflective judgment.

From the response to the study, implications for research outside of the initial intent are also possible. Reflective judgment scores were determined for traditional aged respondents and non-traditional aged respondents with junior and senior academic standings enrolled in businessrelated programs of study in face-to-face and online formats. The differences in reflective judgment were recognized and analyzed between the two age groups. Group mean scores of reflective judgment were also determined based on respondent's gender and were analyzed to 
provide an additional dimension of the construct of reflective judgment, and how it may present itself in this study between the two groups.

This chapter presents results from the analysis of available data obtained from respondents to address the research question: What are the differences among reflective judgment scores of students enrolled in business-related programs due to factors of class rank and program delivery format? The first section of this chapter presents a brief discussion of the demographics and details the distribution of groups of the respondents. This is followed by an explanation and analysis of the data used to address the research question and to conduct other analysis based on respondent demographics. The chapter concludes with a summary of key findings.

\section{Demographics}

\section{Population}

The population was drawn from institutions of higher education with CHEA located in four different states in the southeast portion of the United States. The data obtained from this study is comprised of ninety-seven measurable responses. For a response to be measurable, subjects were required to complete all questions related to at least one ill-structured dilemma within the questionnaire. Any respondent who did not respond to all questions of at least one dilemma was removed from the study. The gender break down of the group was fifty-four (55.6\%) females to forty-three (44.3\%) males. The academic standing break down of the group was thirty juniors, fifty-seven seniors, and ten other. The respondents classified as other did not adhere to the instructions when providing the subject identification in the study, therefore the academic standing of the respondents is unable to be determined. The RCI scores for the 
respondents noted as other will not be utilized in any calculation, therefore a total of eightyseven measurable and identifiable responses were used in this study.

Because research has shown that reflective judgment increases during both educational activities and as age increases, the study sought to obtain responses from traditional age students, but also obtained a large enough quantity of non-traditional aged students to allow for further findings and implications based on age group (King \& Kitchener, 2004). Additionally, the information from demographics composed during data collection allow for other findings and implications based on gender. The collection activities at some institutions did not allow for capturing data solely from students classified as traditional age. However, the instrument gathered demographic data and captured information to allow for attaining this data. This research interprets additional implications beyond the intentions for this study based on selfidentified birth date and additional demographics of respondents.

\section{Distribution of Groups}

Respondents were asked six demographic questions at the start of the questionnaire. Of the 87 measurable and identifiable responses, thirty respondents identified as juniors and fiftyseven were seniors. As shown in Table 2, twenty-two (73.3\%) of the junior students were enrolled in face-to-face programs of study and eight (26.7\%) were enrolled in online programs of study, while fifty-one $(89.5 \%)$ of the senior students were enrolled in face-to-face programs of study and six (10.5\%) were enrolled in online programs of study. As a whole, junior and senior respondents were unbalanced with nearly eighty-four percent of respondents enrolled in face-toface programs of study. 
Table 2

Distribution of data - Academic standing by program delivery format

\begin{tabular}{lcccc}
\hline Academic Standing & \multicolumn{2}{c}{ Face-to-Face } & \multicolumn{2}{c}{ Online } \\
& $\mathbf{N}$ & $\%$ & $\mathbf{N}$ & $\%$ \\
\hline Junior & 22 & 73.3 & 8 & 26.7 \\
Senior & 51 & 89.5 & 6 & 10.5 \\
Total & 73 & & 14 & 16.1 \\
& & 83.9 & & 1.9 \\
\hline
\end{tabular}

The majority $(73.3 \%)$ of students with a junior academic standing were female while students with a senior academic standing were balanced in regards to gender. Overall, total respondents' gender yielded a slightly higher proportion of females (57.5\%; see Table 3).

Table 3

Distribution of data - Academic standing by gender

\begin{tabular}{lcccc}
\hline Academic Standing & \multicolumn{2}{c}{ Male } & \multicolumn{2}{c}{ Female } \\
& N & $\%$ & N & $\%$ \\
\hline Junior & 8 & 26.7 & 22 & 73.3 \\
Senior & 29 & 50.9 & 28 & 49.1 \\
Total & 37 & & & 57.5 \\
& & 42.5 & 50 & \\
\hline
\end{tabular}


As shown in Table 4, nearly two-thirds $(63.3 \%)$ of junior respondents were of traditional age (18 to 24 years) and nearly two-thirds $(64.9 \%)$ of senior respondents were of traditional age. Overall, nearly two-thirds $(64.4 \%)$ of respondents were of traditional age.

Table 4

Distribution of data - Academic standing by age group

\begin{tabular}{lcccc}
\hline Academic Standing & \multicolumn{2}{c}{ Traditional } & \multicolumn{2}{c}{ Non-Traditional } \\
& N & $\%$ & N & $\%$ \\
\hline Junior & 19 & 63.3 & 11 & 36.6 \\
Senior & 37 & 64.9 & 20 & 35.1 \\
Total & 56 & 64.4 & 31 & 35.6 \\
& & & & \\
\hline
\end{tabular}

When considering gender in relation to the program delivery format, slightly more than half $(53.4 \%)$ of respondents enrolled in face-to-face programs of study were female, while a large majority $(78.6 \%)$ of respondents enrolled in online programs of study were female. Overall, fifty $(57.5 \%)$ of the respondents were female and the thirty-seven $(42.5 \%)$ of respondents were male (See Table 5). 
Table 5

Distribution of data-Delivery format by gender

\begin{tabular}{lcccc}
\hline Delivery Format & \multicolumn{2}{c}{ Male } & \multicolumn{2}{c}{ Female } \\
& $\mathbf{N}$ & $\%$ & $\mathbf{N}$ & $\%$ \\
Face-to-Face & 34 & 46.6 & 39 & 53.4 \\
Online & 3 & 21.4 & 11 & 78.6 \\
Total & 37 & & 50 & 57.5 \\
& & 42.5 & & \\
\hline
\end{tabular}

When considering age in relation to the format of program delivery in which respondents were enrolled, the majority $(74.0 \%)$ of respondents enrolled in face-to-face programs of study were of traditional age $(18-24$ years $)$. However, the majority $(85.7 \%)$ of respondents enrolled in online programs of study were of non-traditional age ( 25 years and above). Overall, nearly two-thirds (64.4\%) of respondents were of traditional age (see Table 6).

Table 6

Distribution of data-Delivery format by age group

\begin{tabular}{lcccc}
\hline Delivery Format & \multicolumn{2}{c}{ Traditional } & \multicolumn{2}{c}{ Non-Traditional } \\
& $\mathbf{N}$ & $\%$ & $\mathbf{N}$ & $\%$ \\
\hline Face-to-Face & 54 & 74.0 & 19 & 26.0 \\
Online & 2 & & & \\
& & 14.3 & & \\
Total & 56 & 64.4 & 31 & 35.6 \\
& & & & \\
\hline
\end{tabular}


When considering gender of respondents in relation to age, a large majority $(75.7 \%)$ of male respondents were of the traditional age range (18 - 24 years). Slightly more than half $(56.0 \%)$ of female respondents were of the non-traditional ages (25 years and above). Overall, nearly two-thirds (64.4\%) of respondents were of traditional age (See Table 7).

Table 7

Distribution of data - Gender by age group

\begin{tabular}{lcccc}
\hline Gender & \multicolumn{2}{c}{ Traditional } & \multicolumn{2}{c}{ Non-Traditional } \\
& $\mathbf{N}$ & $\boldsymbol{\%}$ & $\mathbf{N}$ & $\%$ \\
\hline Male & 28 & 75.7 & 9 & 24.3 \\
Female & 28 & 56.0 & 22 & 44.0 \\
Total & 56 & & 31 & 35.6 \\
& & 64.4 & & \\
\hline
\end{tabular}

As shown in Table 8, nearly all respondents with a junior academic standing were White/Caucasian (96.7\%) and one student was African American/Black (3.3\%). The majority of respondents with a senior academic standing were also White/Caucasian (85.9\%), while five $(8.8 \%)$ of respondents were identified as Asian/Pacific Islander, and three (5.3\%) identified as African American/Black. Additionally, 100 percent of respondents enrolled in online programs of study were identified as White/Caucasian. Overall, most respondents (89.7\%) identified as White/Caucasian in this study. 
Table 8

Distribution of data - Racial affiliation by academic standing

\begin{tabular}{|c|c|c|c|c|c|c|}
\hline \multirow[t]{2}{*}{ Racial Affiliation } & \multicolumn{2}{|c|}{ Junior } & \multicolumn{2}{|c|}{ Senior } & \multicolumn{2}{|c|}{ Total } \\
\hline & $\mathbf{N}$ & $\%$ & $\mathbf{N}$ & $\%$ & $\mathbf{N}$ & $\%$ \\
\hline African America/Black & 1 & 3.3 & 3 & 5.3 & 4 & 4.6 \\
\hline Asian/Pacific Islander & 0 & 0.0 & 5 & 8.8 & 5 & 5.7 \\
\hline White/Caucasian & 29 & 96.7 & 49 & 85.9 & 78 & 89.7 \\
\hline Total & 30 & 100 & 57 & 100 & 87 & 100 \\
\hline
\end{tabular}

As shown in Table 9, a large majority of respondents with a junior academic standing were non-Hispanic (90.0\%) and three were Hispanic (10.0\%). Nearly all of the respondents with a senior academic standing were also Non-Hispanic $(99.2 \%)$, while one (1.8\%) respondent was identified as Hispanic. Additionally, 100 percent of respondents enrolled in online programs of study were identified as Non-Hispanic. Overall, most respondents (95.4\%) identified as NonHispanic in this study. 
Table 9

Distribution of data - Ethnicity by academic standing

\begin{tabular}{lcccccc}
\hline Ethnicity & \multicolumn{2}{c}{ Junior } & \multicolumn{2}{c}{ Senior } & \multicolumn{2}{c}{ Total } \\
& $\mathbf{N}$ & $\mathbf{\%}$ & $\mathbf{N}$ & $\boldsymbol{\%}$ & $\mathbf{N}$ & $\boldsymbol{\%}$ \\
\hline Hispanic & 3 & 10.0 & 1 & 1.8 & 4 & 4.6 \\
Non-Hispanic & 27 & 90.0 & 56 & 99.2 & 83 & 95.4 \\
Total & 30 & 100 & 57 & 100 & 87 & 100 \\
& & & & & & \\
\hline
\end{tabular}

Difference in Reasoning about Critical Issues Scores based on Academic Standing

Using King and Kitchener's Reasoning about Critical Issues questionnaire, the respondents could score between stage 2 and stage 7 . From the responses to the questionnaire, each student received an output score for each ill-structured scenario and received a calculated overall RCI score. Since the RCI instrumentation is only used to interpret groups and not individuals, the individual scores of respondents are not shown in this study.

On average, senior respondents in this study experienced higher RCI scores $(M=4.807$, $S E=0.120)$ than junior respondents $(M=4.642, S E=0.213)$, although this difference was not statistically significant $(t=-0.725 ; d f=85 ; p=.107)$ and represented a small degree of association $(r=0.012$; see Table 10). 
Table 10

Distribution of data - RCI group mean score by academic standing

\begin{tabular}{lccc}
\hline Academic Standing & $\begin{array}{c}\text { Face-to-Face } \\
\text { Mean Score }\end{array}$ & $\begin{array}{c}\text { Online } \\
\text { Mean Score }\end{array}$ & $\begin{array}{c}\text { Total } \\
\text { Mean Score }\end{array}$ \\
\hline Junior & 4.524 & 4.968 & 4.642 \\
Senior & 4.735 & 5.412 & 4.807 \\
& & & \\
\hline
\end{tabular}

Other Findings of Differences in Reflective Judgment Scores

Differences in Reasoning about Critical Issues Scores based on Age Group

On average, non-traditional aged respondents in this study showed higher RCI scores ( $M$ $=4.869, S E=0.167)$ than traditional aged respondents $(M=4.684, S E=0.139)$, although this difference was not statistically significant $(t=-0.822 ; d f=85 ; p=.370)$ and represented a small degree of association $(r=0.040$; see Table 11).

Table 11

Distribution of data - RCI group mean score by age group

\begin{tabular}{lccc}
\hline Age Group & $\begin{array}{c}\text { Junior } \\
\text { Mean Score }\end{array}$ & $\begin{array}{c}\text { Senior } \\
\text { Mean Score }\end{array}$ & $\begin{array}{c}\text { Total } \\
\text { Mean Score }\end{array}$ \\
\hline Traditional & 4.680 & 4.687 & 4.684 \\
Non-Traditional & 4.578 & 5.029 & 4.869 \\
& & & \\
\hline
\end{tabular}




\section{Differences in Reasoning about Critical Issues Scores based on Gender}

On average, female respondents in this study had higher RCI scores $(M=4.816, S E=$ $0.138)$ than male respondents $(M=4.661, S E=0.171)$, although this difference was not statistically significant $(t=-0.714 ; d f=85 ; p=.505)$, and represented a small degree of association $(r=0.055$; see Table 12$)$.

Table 12

Distribution of data - RCI group mean score by gender

\begin{tabular}{lccc}
\hline Age Group & $\begin{array}{c}\text { Junior } \\
\text { Mean Score }\end{array}$ & $\begin{array}{c}\text { Senior } \\
\text { Mean Score }\end{array}$ & $\begin{array}{c}\text { Total } \\
\text { Mean Score }\end{array}$ \\
\hline Male & 4.693 & 4.652 & 4.661 \\
Female & 4.624 & 4.967 & 4.816 \\
\hline
\end{tabular}

Summary of Key Findings

The purpose of this study was to analyze reflective judgment scores of students due to factors of class rank and program delivery format of students enrolled in business-related programs of study at institutions of higher education. The quantity of respondents did not allow for analysis of reflective judgment through the utilization of the RCI instrumentation based on the factor of program delivery format. Data obtained from the questionnaire did allow for analysis of other factors, including class rank, age group, and gender. The differences between rank, age group, and gender are examined in this study. Note, however, that only rank was predetermined to be an independent variable of a-priori null hypothesis testing.

In this study, eighty-seven undergraduate students enrolled in business-related programs of study at seven institutions of higher education with CHEA completed this questionnaire 
during the fall 2011, spring 2012, and summer 2012 semesters. Thirty of the respondents represented the junior standing and fifty-seven were seniors. The majority of respondents were of traditional age $(64.4 \%)$, but non-traditional age respondents represented nearly thirty-six percent of the sample. Thirty-seven of the respondents were male and fifty were female. The majority (89.7\%) of the sample were White/Caucasian, while African American/Black students represented just fewer than five percent and Asian/Pacific Islander at just below six percent.

Considering the analysis based on class rank, senior students in this study had higher RCI scores than junior students, but was not statistically significant $(t=-0.725 ; d f=85 ; p=.107)$. We therefore fail to reject the null hypothesis that there is no significant difference between levels of class rank.

Examining RCI scores of respondents based on age group, non-traditional students in this study experienced a higher RCI score than traditional students, but was not statistically significant $(t=-0.822 ; d f=85 ; p=.370)$. Finally, the RCI of respondents based on gender showed that female students in this study experienced a higher RCI mean score than male students, but was not statistically significant $(t=-0.714 ; d f=85 ; p=.505)$. We therefore fail to reject the established null hypothesis. Since the null hypothesis states that the mean RCI score for juniors and seniors would be equal, these findings lead to the understanding that there is no significant difference between gender or between age group. 


\title{
CHAPTER V - CONCLUSIONS, IMPLICATIONS, AND RECOMMENDATIONS
}

\author{
Introduction
}

This chapter discusses the results of this study and presents the conclusions, implications, and recommendations. The conclusions are directly related to the hypothesis and literature presented, and other conclusions are linked to the findings. The implications are drawn from the comparison of reflective judgment management (RJM) scores of students in business-related fields of study, and the manifestation of this construct in online programs of study are based upon data as they relate to the institutions of higher education and policy decisions derived from such data. Further implications related to employment of an instrument protected by proprietary restraints in relation to data collection in this type of study are discussed, and recommendations for future practice and research are presented.

\section{Review of Chapters I - IV}

The purpose of this study was to analyze RJM mean scores of students based on factors of class rank and program delivery format for business-related programs of study at institutions of higher education accredited by the Council of Higher Education (CHEA). Because businessrelated fields of study often utilize activities that are citied to promote reflective judgment and likely require students to employ problem-solving skills regularly, it is important to better understand this group of student's reflection about their suppositions about knowing and development of reflective judgment in higher education settings (Wolcott \& Lynch, 1997; Ilacqua \& Prescott, 2003; Thorseth, 2008). The significance of investigating the relationship of reflective judgment and educational activities supports educators toward more fully understanding how to prepare graduates to handle ill-structured problems they will face in life beyond college. This understanding, in turn, can support the creation of activities that enhance 
development and ensure students are not only prepared to evaluate the content of a course, but also to navigate situations that await them in the communities outside of the institution. If students enrolled in business-related programs of study score differently in reflective judgment based on the RCI, is it influenced by academic standing and/or program delivery format? Limited response rates from online students were achieved, so data available to make comparisons due to factors of class rank are analyzed, but a statistically significant conclusion based on delivery format is not examined.

Class rank was identified as a category to compare the mean score of juniors to seniors in RJM utilizing the RCI quantitative instrument. The RCI instrumentation has been shown to measure group differences, so individual changes are not identified in this study. Since the population of the group must be controlled, a challenge in the utilization of this type of instrument existed when making inferences about groups for a limited number of systematic variances and the analysis of external factors that may contribute to unsystematic variances. A solution previously existed with the RJI that measured reflective judgment on an individual basis and allowed for inferences on individuals, but opportunities to become a trained and certified evaluator of the instrument to utilize in understanding reflective judgment of individuals is no longer offered (http://www.umich.edu/ refjudg/reflectivejudgmentinterview.html).

The population consisted of students enrolled in business-related programs of study among seven institutions of higher education with CHEA. The independent variables were: a) class rank grouped as junior or senior, b) age group assembled as traditional and non-traditional age, and c) gender grouped as male and female. The dependent variable was the reflective judgment score employing the RCI for determination. Because of a low response rate from 
online programs of study, this research employed the independent sample $t$-test to make comparisons of RCI mean scores of respondents in all three scenarios.

To provide a way to make comparisons and ensure respondents obtained their anonymity, subject identification with three components were developed and provided to students. An instruction sheet which described the study accompanied the questionnaire. Respondents' voluntary participation was requested in the instruction sheet, and respondents were provided with a range of subject identifiers to select when beginning the study. The subject identification included an identifier to determine academic standing, institution, and delivery method for each participant. Because the instrument did not have the capability to require students to enter valid subject identification before beginning or completing the questionnaire, several respondents erroneously entered unidentifiable subject identification and thus are not considered in this study. The instrument is currently being used as part of a large data collection activity to inform RCI norms on a broader scale, and provides further support for the overall research on RJM using the RCI instrumentation (http://www.reflectivejudgment.org/research.cfm).

Conclusions Related to Hypothesis and Research Question

The null hypothesis for this study states that the mean RCI score for juniors and seniors would be equal. Expressed mathematically:

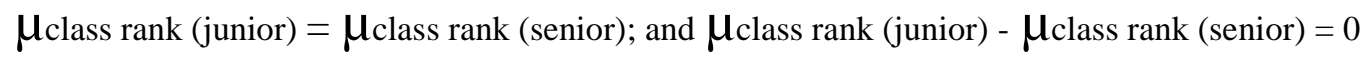

The research question is: What are the differences among reflective judgment scores of students enrolled in business-related programs due to factors of class rank and program delivery format?

The RCI scores based on class rank showed that senior respondents scored at slightly higher levels of reflective judgment than junior respondents. While there was more uniformity 
in the senior population with $S D=.907$ than the junior population with $S D=1.168$, the difference in mean scores was not proven to be statistically significant at $a>0.05$. The results of the study show that both junior and senior students scored in stage four of reflective judgment with a mean score equaling 4.807 for seniors and 4.642 for juniors.

Individuals in stage four are classified in the RJM as quasi-reflective thinkers. Students who exhibit quasi-reflective thinking recognize that ill-structured problems may not have one correct answer, but struggle to differentiate personal beliefs from organized and produced analysis and conclusions (Wood, 1997). While student understanding has expanded to recognize that ill-structured problems exist, individuals in stage four are unable to use data appropriately in order to draw conclusions (Evans et al., 1998). Individuals in stage four justify answers when evaluating data in an individual manner, "choosing evidence that fits an established belief" (King \& Kitchener, 1994, p. 61), and when faced with opinions that differ from their own, they draw the conclusion that others must have misinterpreted the data to reach a different conclusion. Individuals in stage four thinking begin to shift focus in stage five reasoning as they modify their thinking to investigate how their understanding may be reasoned from multiple perspectives (King \& Kitchener, 1994).

While the increase in RCI scores appear to be small in numerical terms, it is the differentiation in the way that thinking occurs between the stages that are important to note (King \& Kitchener, 1994; Pascarella \& Terenzini, 2005). Individuals in stage four often justify their beliefs by providing rationalization that is regularly individualistic, while in stage five beliefs are reasoned contextually using systematic investigations of inquiry (King \& Kitchener, 1994). The significance in the quantitative size of change is less significant than the qualitative change in thinking that occurs at this level (Pascarella \& Terezini, 2005). Previous research by 
King and Kitchener (1994) also show a modest difference in mean scores with freshman students averaging 3.6 and senior samples having a median score of 4.0.

One should be careful when making inferences between studies that employ the RJI with research utilizing the RCI. According to Sheila Thompson, PhD, who oversees all data with the RCI, "some caution should be used in interpreting that average score, as well, given that the RCI is a recognition task as compared to the production task that is the RJI (reflective judgment interview) on which much of the previous research is based." Additionally "[m]ost RCI data reveal averages that are about a stage higher than did RJI data for comparable populations" (S. Thompson, Personal Communication, September, 16, 2012).

\section{Other Conclusions}

In addition to the research question posed in this study, additional conclusions can be drawn from the data obtained from respondents. These conclusions relate to demographic characteristics of participants.

\section{Demographic Findings}

As illustrated in Tables 7 and 8 in Chapter Four, a large majority of online respondents were of the non-traditional age $(85.7 \%)$ female $(78.6 \%)$. This finding is similar to previous research in the area of demographics of online students, in which Diaz and Cartnal (1999) experienced a higher percentage of non-traditional aged and female students, and West (2010) reported over half, or fifty-seven percent, of respondents to be female, and experienced a large majority, eighty percent, of the respondents to be non-traditional aged.

\section{RCI Mean Scores Based on Age}

The characteristics of age-related differences to RJM have previously been examined in research. In King and Kitchener (2004), non-traditional students without attainment of college 
degrees scored 3.6, while non-traditional aged respondents with college degrees scored a mean score of 4.3 on the RJI. In analysis of cross-sectional studies, the average reflective judgment score using the RJI found that traditional aged respondents with junior academic standing scored 3.74, while traditional aged seniors scored 3.99 (King \& Kitchener, 1994). Additionally, nontraditional aged respondents with senior academic standing scored nearly the same as traditional age respondents at 3.98. Continuing with this research, when analyzing reflective judgment scores of non-traditional students to traditional students at the same academic standing, the resulting scores appear to be similar between the two groups, showing that non-traditional students do not appear to vary significantly from traditional students for reflective thinking (King \& Kitchener, 1994).

In this study, the RCI mean scores based on age showed that non-traditional aged respondents scored at slightly higher levels of reflective judgment than traditional aged respondents, but as shown in King and Kitchener (1994) this difference was not significant. While greater uniformity existed in the non-traditional population with $S D=.927$ than the traditional aged population with $S D=1.042$, the difference in mean scores was not proven to be statistically significant at $a>0.05$. The results of the study show that both junior and senior students scored in stage four of reflective judgment with a mean score equaling 4.869 for nontraditional aged and 4.684 for traditional aged respondents.

\section{RCI Mean Scores Based on Gender}

Although comparisons of the gender differences of reflective judgment were not the focus for this study, the demographics gathered from the RCI instrumentation provides an opportunity to explore this characteristic. As shown in Chapter Two of this study, moral improvement, reasoning, and consideration of others may be related to reflective judgment (King 
\& Kitchener, 2004). Other research in the area of moral development and consideration for others has shown that females tend to score higher when considering moral judgment issues (Eisenberg, et al, 2005).

The RCI scores based on gender showed that female respondents scored at slightly higher levels of reflective judgment than male respondents. While more uniformity existed in the female population with $S D=.978$ than the male population with $S D=1.104$, the difference in mean scores was not proven to be statistically significant at $a>0.05$. The results of the study show that both female and male students scored in stage four of reflective judgment with a mean score equaling 4.816 for females and 4.661 for males. When considering the three ill-structured scenarios, female respondents scored highest on the scenario involving immigration subject matter while men scored higher on the scenario dealing with work force issues than the other scenarios. Since conflicting patterns of data exists in the area of gender comparisons among previous studies, the relationship of gender and reflective judgment pose opportunities for further consideration (King \& Kitchener, 1994).

\section{Sample Population}

Because of the limited sample size, it is a possibility that this study does not represent the general population. If there had been larger data sets for each category, the effects of a factorial ANOVA could have provided additional analysis and allowed the researcher to consider additional categories related to reflective judgment development. The results that are possible through an analysis of a factorial ANOVA may have revealed additional conclusions not anticipated in this study. 


\section{Implications}

Drawn from the findings and conclusions of this study, seven implications are provided: 1) academic standing comparison; 2) accompanying factors; 3) demographics characteristics; 4) sample size; 5) data collection with proprietary instrumentation; 6) nature of instrument, and; 7) policy concerns.

\section{Academic Standing Shows Improvement}

The independent variable of academic standing in this study showed that senior respondents had higher RCI mean scores than juniors, although not statistically significant at $a>$ 0.05 . While academic standing is not positioned as a true significant factor in increases in reflective judgment, the increase based on academic standing does support findings from previous literature that show development of reflective judgment based on academic standing (King \& Kitchener, 1994). The development of reflective judgment may have been greater if a comparison between freshmen and sophomore samples were included in this study, as longitudinal studies of reflective judgment have shown greater changes in reflective judgment when the length of time between tests is greater (King \& Kitchener, 1994).

While many studies have compared online learning to face-to-face environments, the study of online learning is still in the early phases, and research-based strategies for online education are still developing (O’Malley \& McCraw, 1999). As demonstrated in Chapter Two, many conflicting perspectives continue to emerge and exist over time. If these perspectives are not investigated scientifically, then the divergence in opinions of faculty will only continue to enlarge as online coursework further permeates academics (Allen \& Seaman, 2012). If one adheres to the belief that educational activities in the online environment should not be discounted despite the differences in instruction through the use of technology, then one can only 
assume that the emergence of reflective judgment of online programs of study may have similar trends as face-to-face programs (Zhao et al., 2005).

Accompanying Factors Characterize Non-Significant Effect on Reflective Judgment

Considering the demographic characteristics of age and gender, non-traditional aged students had higher levels of reflective judgment than traditional aged students, and female students experienced higher scores than did their male counterparts. While both gender and age certainly matter in this study - resulting in non-traditional, female students receiving the greatest impact in terms of reflective judgment during their educational experiences - neither of these factors proved to be statistically significant at $a>0.05$. These collective factors do not establish themselves as a precise or significant cause of increases in reflective judgment in this study. Age, however, continues to be an interesting consideration, since many adult students are enrolled part-time and take longer to graduate, and often have additional life experiences that may play a role in their reasoning and affect reflective judgment scores (King \& Kitchener, 1994). Therefore, consideration of lifelong learning and informal education that takes place through life experiences may provide interesting insight for those in higher education in investigating how credit may be awarded for learning that occurs outside of the classroom. These results suggest that informal learning may produce advancement of reflective judgment and provide higher education with an opportunity for creation of models that take advantage of such development.

\section{Demographic Consideration of Online Population}

As the evolving landscape of online education continues to take shape, it may be necessary to investigate ways that differences in other demographic characteristics may affect development of reflective judgment through online coursework in higher education. As 
identified in this study and previous research, a majority of the online student population was female and strong majorities were non-traditional aged (Diaz \& Cartnal, 1999; West, 2010). While research has shown that reflective judgment increases through instructional activities during higher education, as well as during life experiences as individuals age (King \& Kitchener 1994, 2004; Braxton, Hirschy \& McClendon, 2004), these considerations may be a significant factor when interpreting reflective judgment of online programs factor in the future.

\section{Larger Sample Size May Improve Significance}

To complete an analysis through RCI, the minimum sample size must be equal or greater to thirty measureable responses. In the case of a comparison based on academic standing, a Levene's significance at a one-tail approached .054. An increased sample size might have proven the "tails" in each of these scenarios to be significant. To have completed an analysis based on program delivery format in this study, it would require an additional twenty-two measurable responses from juniors and twenty-four measureable responses from seniors enrolled in online programs of study. To ensure the data is representative of the population of this study, a random selection process that parallels this study would be necessary. A large sample size may also allow for additional analysis that could enhance the study not anticipated by the researcher.

\section{Nature of Instrument}

The RCI instrumentation uses three separate ill-structured scenarios to establish an average response and come to a reflective judgment score for participants. The three illstructured scenarios in this instrumentation include topics on work force, alcoholism, and immigration. While the scenarios are designed to investigate the process individuals go through to form a decision, it may be possible that the ill-structured scenario itself plays a role in the reasoning process that students use to form their decisions. When analyzing the independent 
variable of academic standing, gender, and age, the ill-structured scenario of immigration showed the smallest standard deviation of all scenarios, meaning that the scores of reflective judgment when forming decisions based on the immigration scenario found that individuals within each group scored more similarly than in other scenarios. Additionally, non-traditional aged students scored the highest in the work force scenario, while traditional aged students scored highest in the immigration scenario. In fact, three female respondents scored the highest level of reflective judgment at 7.0 in the study on the immigration scenario. Familiarity with the ill-structured scenario or personal experience may have caused this scenario to be less of an illstructured problem for these students. If this is the case, other factors including personal experience and difference in education between participants in this study may be in play.

Since the intent of this study was to ensure complete anonymity for the participants, additional contact regarding readability and factors related to completing the instrument were not sought, although previous research has identified potential challenges for respondents when employing the RCI instrumentation. Maskey (2010) had concerns with "instrument difficulty and readability [as well as a]... possible fatigue factor for students as they read each of the three dilemmas of the RCI test, [and] response bias as they got further into the instrument with each dilemma" (pg. 91) were recognized when employing the RCI. These factors may make this instrument difficult in certain research scenarios and likely diminish response rates and affect responses from those who do participate. As the instrument requires considerable commitment from respondents, timing and external factors may have influence on a participant's willingness to approach the questionnaire in a manner needed to garner a meaningful response. Strong consideration in these areas should be made when employing this instrument. 


\section{Utilization of Proprietary Instrument in Research}

While researching reflective judgment, two instruments were identified as being developed to measure reflective judgment. The RJI, a qualitative instrument used to interpret individual reflective judgment, was used through delivery of an interview protocol by a trained interpreter of the RJI. Currently, training for this instrument is not available and thus this instrument is not currently available for research. The RCI, a quantitative instrument that measures group mean scores, is available and supports reflective judgment score interpretations for groups. This instrument is guarded by proprietary constraints through a collaborative effort with the University of Michigan.

While this instrument can be very effective in situations where a researcher is able to personally garner the attention of participants, some practical difficulties in collecting data in this form of research, and from a wide-array of institutions, is challenging. Complications associated with collecting data from an independent research approach have made it difficult to garner large samples of respondents to make comparisons among diverse institutions of higher education.

As an external researcher, this type of study does not lend itself easily to research, rather the instrument can be more appropriately used when institutions have improved access to students and are able to track participation as part of the mission of the institution. From an external researcher's position, relationships with institutions are absolutely necessary to take a broad view of reflective judgment using the RCI and better understand how the construct of reflective judgment can be viewed in both traditional and online learning environments.

\section{Policy Concerns}

While online learning continues to expand throughout higher education, limited research of the effectiveness of online instruction compared to traditional formats is available (Angiello, 
2010). In this study, it was difficult to capture the participation of institutions with only online programs of study. The respondents from this study were obtained from six public and one private not for profit institution, but even in these situations it was difficult to obtain participation from online students. The difficulty experienced in this study may shed light on why limited research in the area of online learning exists to date.

The need to discover avenues for cultivating ways of thinking and enhancing reasoning in college should be an area of importance to all faculty, administrators and policy-makers in higher education, and all others "who have a vested interest in having adults be able to make informed decisions in their personal lives, in the workplace, and in their communities" (King \& Kitchener, 2002, p. 54). Ensuring students are equipped with the knowledge and capacity to make ethical and reflective decisions should not only be a goal but a requirement of institutions of higher education (King \& Kitchener, 1994). Graduates need to understand that ill-structured questions exist; they need to understand how to go about solving such issues and understand that coming to the conclusions that uncertainty exists in certain circumstances is a main characteristic in the exploration for knowledge (Dewey, 1933).

Differing opinions abound about the comparison of online and traditional learning environments (Allen \& Seaman, 2012). Because of the vast differences that exist between each learning modality and the process of how "knowing occurs," generalities of this study are not able to be made for the online learning environment. In a study by Allen and Seamen (2012) results show that seventy-nine percent of responding faculty have apprehensions about the quality of for-profit institutions. Continuing with this study, differing opinions and concerns of online education endure, even with growing enrollment, and from chief academic officers who consider online learning to be critical to the long-term strategy of higher education institutions. 
Because of the vast expansion of distance education and the further penetration of fully online programs of study at institutions of higher education, it is necessary for interested parties to be informed about comparisons in different academic settings. A more informed public supports more informed decisions, better prepared faculty support improved curriculum and effective learning environments, and a more informed administration supports better data-driven decisions and policy development that supports the evolving climate of higher education. Data is necessary to inform decisions and identify avenues for improvement. In many instances, core indicators are utilized to determine how one institution is operating in relation to another similar institution. In other areas of operations, budgets may be determined at the local or state level when allocations are considered.

While many institutions continue to show growth in online learning and have begun incorporating online learning into their strategic plans, reducing the infrastructural strain by minimizing administrative duplication, and even viewing the delivery format as a significant part of an institution's long term strategies for success (Hiltz \& Turoff, 2005; Picciano, 2006; Picciano, Seaman, \& Allen, 2010), consideration must be made when developing coursework in an online environment to ensure the opportunity to evaluate and assess student progress, and to ensure instruction is provided to develop cognitive and reflective abilities in students. Additional challenges for cultural diversity exist in the online learning environment (Rogers et al., 2004; Wang, 2007; Tan, Nabb, Aagard, \& Kim, 2010). Inherent advantages exist in both traditional and online settings, and these must be understood and employed so that educators are fully aware of how to leverage strategies to support students in all formats of delivery and advance accreditation initiatives. 
While the need to measure reflective judgment may not currently find itself on the Top 10 Higher Education State Policy Issues for 2012, the lack of data, diverging opinions, and assumptions do not provide answers to questions or solutions to problems. Valid and reliable data sets must be available for scholars to review and discuss.

\section{Recommendations for Future Practice}

The recommendations presented are based upon the findings and conclusions of available data from respondents. The recommendations for future practice is that leaders in higher education should explore how the construct of reflective judgment occurs during collegiate activities and seek opportunities to enhance available data to make informed decisions about the activities that best enhance our understanding in what situations enrich development of reflective judgment. Further expansion of technology and online delivery are inevitable. Demands to make more data-driven decisions in higher education, including performance based funding, perpetuate the need to examine all areas of higher education and provide studies that help establish "best practices" and ensure graduates are prepared for life beyond college.

Four recommendations for practice are offered: 1) replicate of study with larger sample size; 2) explore further development of reflective judgment based on age differences; 3) explore how the construct of reflective judgment may present itself in online format of study, and; 4) develop streamlined assessments of reflective judgment.

First, it is necessary to replicate this study with a larger sample size that, in particular, includes respondents from online programs of study. While this study was successful in obtaining responses from juniors and seniors, the recommendation is to obtain a better understanding of reflective judgment and the significance of growth during college years, freshmen through graduation. In this regard, comparisons with online programs of study would 
enable a more robust analysis. Although previous studies employing the RJI to assess reflective judgment have not show differences based on region of the US or ethnicity, more categories should be explored during analysis, including more geographic, racial, and ethnic representation, thus ensuring the study obtains a broader audience to reveal developments that may exist within this larger data set (King \& Kitchener, 1994).

Second, factors related to educational activities and age have been shown to influence reflective judgment scores. Minimal research has examined the degree of variance of reflective judgment based on age versus educational activities. The recommendation is to examine participants through a longitudinal study and conduct factorial analysis of variance to identify if degree of variance for age versus educational activities can be more fully determined. It would be necessary to follow similar groups of individuals with a systematic variance of those enrolled in college versus those not enrolled in college. Further demographic data could also be obtained to allow for controlled of unsystematic variances when conducting the analysis.

Third, most of studies to date in regards to online learning have investigated outcomes related to student success, such as passage rate, persistence, attitudes, and other aspects of highrisk students (Diaz \& Cartnal, 1999). But minimal research regarding the development of more process-oriented phenomena like reflective judgment has been conducted. Future research should investigate reflective judgment and how knowing occurs in the online learning environment. Insights from this research should then identify what contributes to growth of reflective judgment in this environment. How reflective judgment develops in learning environments that combine traditional learning environments with online learning environments (blended environments) should also be investigated. Additional research can support 
institutional understanding about the development of a broad range of learning prior to contributing large amounts of funds toward online learning (Angiello, 2010).

Fourth, the challenge that remains for interpretation of reflective judgment is for the educational community to create a more streamlined instrument to assess reflective judgment. Preferably, faculty would be able to assess reflective judgment by inserting this assessment in the curriculum. This instrument could be structured to obtain data from students in their first experience at an institution, and conduct continuous inquiries throughout the students' college career. This will help ascertain the influence of an academic program, as well as additional activities at the institution, which may have contributed to the development of reflective judgment. Ideally, if resources are available, this longitudinal assessment can be conducted by an institution to identify the activities with the greatest influence on reflective judgment during college.

Additional data that is longitudinal in nature, and provides cross-data analysis, supports research by providing secondary data available to researchers to investigate how the construct of reflective judgment may be developing in a wide-array of institutional settings. As many educators have acknowledged difficulty in understanding observations of students to determine ways they defend their beliefs, a challenge persists for faculty to continue to develop models of support in this evolving landscape of higher education in order to expand understanding and develop a culture of learning that continues to provide students with appropriate environments for cognitive and social development (Whipp \& Lorentz, 2008).

An instrument that supports ongoing research of the RCI and RJI can support the education community's understanding of reflective judgment and how to increase opportunities for student growth in this necessary area in today's society. The Carnegie Foundation, an 
institution designed to advance research and development to improve teaching, has recently developed a research and development structure that encourages higher education to learn from one another and combine lessons from "scholarship and practice...[and] deploy what we learn about what works in schools and classrooms, and add to our knowledge to continuously improve the performance of the system" (www.carnegie foundation.org/improvement-research/approach).

As we do not fully understand how development of reflective judgment may compare in online learning environments, obvious strengths exist as they do in the traditional learning environment. Better understanding of these components to support the effectiveness of learning in each setting by developing activities that can be employed in all areas of academics to enhance reflective judgment. "It is hard to improve what you do not fully understand"

(Carnegiefoundation.org). The best way to expedite this understanding is to learn together; to learn through research, inquiry, and practice. 


\section{Definitions}

Asynchronous - A method of communication in online courses that are not conducted at realtime.

Blended or Hybrid Course ${ }^{1}$ - A course that combines face-to-face instruction, but is supported by online technology to deliver thirty to seventy-nine percent of the course content.

Ill-structured problems - A problem that cannot be solved by an approach that has predetermined steps or sequence.

Online course $^{1}-$ A course that delivers at least eighty percent of its course content online. Synchronous - A method of communication in online courses that are conducted in real-time. Traditional course ${ }^{1}-$ A course that is delivered totally face-to-face without the support of online technology.

Vexing problems - A problem that cannot be solved by an approach that has predetermined steps or sequence.

Web-Facilitated course ${ }^{1}-$ A course that is delivered face-to-face for at least seventy percent of the course material, but uses technology, e.g. web pages, course management systems, for students to acquire and submit assignments or other course content. Well-structured problems - A problem that can be solved by following predetermined steps to come to a definitive answer.

\footnotetext{
${ }^{1}$ Allen, I.E and J. Seaman (2010)
} 


\section{References}

Allen, I.E. \& Seaman, J. (2007). Online nation: Five years of growth in online learning. Retrieved on December 8, 2010, from http://sloanconsortium.org/publications/survey/pdf/online_nation.pdf

Allen, I.E. \& Seaman, J. (2010). Class differences: Online education in the United States, 2010. Retrieved on December 8, 2010, from http://sloanconsortium.org/sites/default/files/class_differences.pdf

Allen, I.E., Seaman, J., Lederman, D., \& Jaschik, S. (2012). Conflicted: Faculty and online education, 2012. Retrieved on Monday, October 1, 2012, from http://www.insidehighered.com/sites/default/server_files/files/IHE-BSRG-Conflict.pdf

Anakwe, U. P., Kessler, E.H., \& Christensen, E.W. (1999). Distance learning and cultural diversity: Potential users' perspective. International Journal of Organizational Analysis (1993 - 2002), 7(3), 224. Retrieved from http://search.ebscohost.com/login.aspx?direct=true\&db=buh\&AN=2784790\&site=ehostlive

Angiello, R. (2010). Study looks at online learning vs. traditional instruction. Education Digest, 76(2), 56. Retrieved from http://search.ebscohost.com.www.libproxy.wvu.edu/login.aspx?direct=true $\& d b=f 5 h \& A N=5$ 3775674\&site=ehost-live

Aragon, S. R., Johnson, S. D., \& Shaik, N. (2001). A preliminary analysis of the influence of learning style preferences on student success in online versus face-to-face environments. A 
paper presented at the eighth International Literacy \& Education Research Network Conference onLearning, Spetses, Greece. Retrieved from citeseerx.ist.psu.edu.

Aragon, S. R., Johnson, S. D., \& Shaik, N. (2002). The influence of learning style preferences on student success in online versus face-to-face environments. American Journal of Distance Education, 16(4), 227. Retrieved from http://search.ebscohost.com/login.aspx?direct=true $\& d b=a 9 h \& A N=9093367 \&$ site=ehost-live

Arbaugh, J., Cleveland-Innes, M., Diaz, S. R., Garrison, D. R., Ice, P., Richardson, J. C., et al. (2008). Developing a community of inquiry instrument: Testing a measure of the Community of Inquiry framework using a multi-institutional sample. Internet and Higher Education, 11, 133-136.

Artino, A. R. \& Stephens, J. M. (2006). Learning online: Motivated to self-regulate? Academic Exchange Quarterly, 10(4), 176-182.

Bauer, K. W. (2001). The effect of participation in undergraduate research on critical thinking and reflective judgment. AIR 2001 annual forum paper. Retrieved from http://search.ebscohost.com/login.aspx?direct=true \&db=eric \&AN=ED457747\&site=ehost-

Betts, K., Hartman, K., \& Oxholm III, C. (2009). Re-examining \& repositioning higher education: Twenty economic and demographic factors driving online and blended program enrollments. Journal of Asynchronous Learning Networks, 13(4), 3-23. Retrieved from http://search.ebscohost.com/login.aspx?direct=true \&db=ehh\&AN=47390151\&site=ehostlive 
Bold, M., Chenoweth, L., \& Garimella, N. K. (2008). BRICS and clicks. Journal of Asynchronous Learning Networks, 12(1), 5-25. Retrieved from http://search.ebscohost.com/login.aspx?direct=true \&db=eric\&AN=EJ837466\&site=ehostlive; http://www.sloanconsortium.org/publications/jaln/v12n1/v12n1_2bold_member.asp live

Bolliger, D. U., \& Shepherd, C. E. (2010). Student perceptions of ePortfolio integration in online courses. Distance Education, 31(3), 295-314. doi:10.1080/01587919.2010.513955

Braxton, J. M., Hirschy, A. S., \& Mcclendon, S. A. (2004). Understanding and reducing college student departure. ASHE-ERIC Higher Education Report: Volume 30, Number 3. San Francisco: Jossey-Bass.

Bryk, A. S., Gomez, L. M., Grunow, A., \& Carnegie Foundation for the Advancement of, T. (2010). Getting Ideas into Action: Building Networked Improvement Communities in Education. Carnegie Perspectives. Carnegie Foundation for the Advancement of Teaching.

Center for the Study of Higher and Postsecondary Education. (2009). Retrieved March 25, 2009, from http://www.umich.edu/ refjudg/index.html.

Ciges, A. S. (2001). Online learning: New educational environments in order to respect cultural diversity through cooperative strategies. Intercultural Education, 12(2), 135-147. doi:10.1080/14675980120064782

Costa, C. (2009). Use of online information resources by rmit university economics, finance, and marketing students participating in a cooperative education program. Australian Academic 
\& Research Libraries, 40(1), 36-49. Retrieved from http://search.ebscohost.com.www.libproxy.wvu.edu/login.aspx?direct=true $\& d b=a 9 h \& A N=$ 39144536\&site=ehost-live

Churchman, C. W. The design of inquiring systems: Basic concepts of systems and organizations. New York: Basic Books, 1971.

Davison, M. L., King, P. M., Kitchener, K. S., \& Parker, C. A. (1980). The stage sequence concept in cognitive and social development. Developmental Psychology, 16(2), 121-131. doi:10.1037/0012-1649.16.2.121

Dewey, J. (1933). How we think. D.C. Heath and Co, Boston, MA.

Diaz, D. P., \& Cartnal, R. B. (1999). Students' learning styles in two classes: Online distance learning and equivalent on-campus. College Teaching, 47(4), 130-35. Retrieved from http://search.ebscohost.com.www.libproxy.wvu.edu/login.aspx?direct=true \&db=eric\&AN= EJ606686\&site=ehost-live

Diaz, S. R., Swan, K., Ice, P., \& Kupczynski, L. (2010). Student ratings of the importance of survey items, multiplicative factor analysis, and the validity of the community of inquiry survey. Internet and Higher Education, 13, 22-30.

Díaz, S. R. (2011). Knowledge Management as an approach to evaluating advanced graduate programs. In Callejo-Pérez, D., Fain, S. M., \& Slater, J. J. (Eds.). Higher education and human capital: Re/thinking the doctorate in America. Sense Publishers. 
Dobbs, R. R., Waid, C. A., \& del Carmen, A. (2009). Students' perceptions of online courses: The effect of online course experience. Quarterly Review of Distance Education, 10(1), 926. Retrieved from http://search.ebscohost.com.www.libproxy.wvu.edu/login.aspx?direct=true $\& d b=a 9 h \& A N=$ $42734027 \&$ site $=$ ehost-live

Downey, J. A., \& Blue Ridge Community Coll, Weyers Cave, VA Office of,Institutional Research. (2002). Developing reflective judgment in community college students: Employing the writings of wilson in a program of contextual support. A student development research proposal. Retrieved from http://search.ebscohost.com/login.aspx?direct=true \&db=eric\&AN=ED471644\&site=ehostlive

Ellis, R. A., Calvo, R., Levy, D., \& Tan, K. (2004). Learning through discussions. Higher Education Research \& Development, 23(1), 73-93. doi:10.1080/0729436032000168504

Eisenberg, N., Cumberland, A., Guthrie, I. K., Murphy, B. C., \& Shepard, S. A. (2005). Age changes in prosocial responding and moral reasoning in adolescence and early adulthood. Journal of Research On Adolescence (Blackwell Publishing Limited), 15(3), 235-260. doi:10.1111/j.1532-7795.2005.00095.x

Evans, Nancy J., Forney, Deanna S., and Guido-DiBrito, Florence. (1998). Student development in college: Theory, research and practice. San Francisco: Jossey-Bass.

Fields, Andy. (2005). Discovering statistics using SPSS. London: Sage Publications. 
Flavell, John H. (1977). Cognitive development. New Jersey: Prentice-Hall.

Friedman, A. A. (2004). The relationship between personality traits and reflective judgment among female students. Journal of Adult Development, 11(4), 297-304. Retrieved from http://search.ebscohost.com.www.libproxy.wvu.edu/login.aspx?direct=true $\& d b=a 9 h \& A N=$ 14700810\&site=ehost-live

Friend, J., Caruthers, L., \& McCarther, S. M. (2009). Re-living dangerous memories: Online journaling to interrogate spaces of "otherness" in an educational administration program at a midwestern university. Journal of Research on Leadership Education, 4(2), 1-29. Retrieved from http://search.ebscohost.com.www.libproxy.wvu.edu/login.aspx?direct=true $\& d b=$ eric $\& A N=$ EJ875409\&site=ehost-live

Fischer, K. W. (1980). A theory of cognitive development: The control and construction of hierarchies of skills. Psychological Review, 87, 477-531.

Gay, L. R., Mills, Geoffrey E., \& Airasian, Peter. (2006). Educational research: Competencies or analysis and applications. New Jersey: Pearson Education, Inc.

Geith, C., \& Vignare, K. (2008). Access to education with online learning and open educational resources: Can they close the gap? Journal of Asynchronous Learning Networks, 12(1), 105126. Retrieved from http://search.ebscohost.com/login.aspx?direct=true \&db=eric \&AN=EJ837472\&site=ehostlive; http://www.sloanconsortium.org/publications/jaln/v12n1/v12n1_8geith_member.asp 
Gelo, O., Braakmann, D., \& Benetka, G. (2008). Quantitative and Qualitative Research: Beyond the Debate. Integrative Psychological \& Behavioral Science, 42(3), 266-290. Retrieved from http://search.ebscohost.com/login.aspx?direct=true \&db=a9h\&AN=34406349\&site=ehostlive

Guthrie, V. L. (1997). Cognitive foundations of ethical development. New Directions for Student Services, (77), 23. Retrieved from http://search.ebscohost.com/login.aspx?direct=true\&db=a9h\&AN=9708242951\&site=ehostlive

Hoy, W. K., \& Miskel, C. G. (2008). Educational administration: Theory, research, and practice, 8. New York: McGraw-Hill.

Hiltz, S. R., \& Turoff, M. (2005). Education goes digital: The evolution of online learning and the revolution in higher education. Communications of the ACM, 48(10), 59-64. Retrieved from http://search.ebscohost.com/login.aspx?direct=true \&db=buh\&AN=18391444\&site=ehostlive

Hite, N. G. (2011). Research in online education. In L. G. Snyder (Ed.), Online business education (pp. 16 - 28). Reston: National Business Education Association.

Hodge, E. (2011). Instructional design for online education. In L. G. Snyder (Ed.), Online business education (pp. 41 -55). Reston: National Business Education Association. 
Huba, M. E. \& Freed, J. E. (2000). Learner-centered assessment on college campuses: Shifting the focus from teaching to learning. Needham Heights: Allyn \& Bacon.

Hylton, M. E. (2007). Facilitating online learning communities: A comparison of two discussion facilitation techniques. Journal of Technology in Human Services, 25(4), 63-78. doi:10.1300/J017v25n04-04

Ilacqua, J. A., \& Prescott, M. E. (2003). Knowing economic theory: Applying the reflective judgment model in introductory economics. Education, 124(2), 368. Retrieved from http://search.ebscohost.com.www.libproxy.wvu.edu/login.aspx $?$ direct $=$ true $\& d b=f 5 h \& A N=1$ $1980244 \&$ site $=$ ehost-live

Jackson, R. (2008). Information literacy and its relationship to cognitive development and reflective judgment. New Directions for Teaching \& Learning, 2008(114), 47-61. doi:10.1002/tl.316

Jahnke, J. (2010). Student perceptions of the impact of online discussion forum participation on learning outcomes. Journal of Learning Design, 3(2), 27-34. Retrieved from http://search.ebscohost.com.www.libproxy.wvu.edu/login.aspx?direct=true $\& d b=e h h \& A N=$ $50843845 \&$ site=ehost-live

Johnson, B. S. (2011). Business communication courses. In L. G. Snyder (Ed.), Online business education (pp. 155 - 166). Reston: National Business Education Association.

Keegan, D., \& Fern Univ, Hagen (Germany) Inst for Research into,Distance Education. (1995). Distance education technology for the new millennium compressed video teaching. ZIFF 
papiere 101. Retrieved from

http://search.ebscohost.com/login.aspx?direct=true $\&$ db=eric \&AN=ED389931\&site=ehostlive

Kegan, R. (1982). The evolving self: Problem and process in human development. Cambridge: Harvard University Press.

Kipta, A., \& Berge, Z. L. (2006). Process transformations that sustain distance training. Distance Learning, 3(2), 13-21. Retrieved from http://search.ebscohost.com/login.aspx?direct=true \&db=ehh\&AN=22941800\&site=ehostlive

King, P. M. (1992). How do we know? Why do we believe? Liberal Education, 78(1), 2. Retrieved from http://search.ebscohost.com/login.aspx?direct=true $\& d b=f 5 h \& A N=9608042120 \&$ site=ehost live

King, P. M. (2000). Learning to make reflective judgments. New Directions for Teaching \& Learning, (82), 15. Retrieved from http://search.ebscohost.com.www.libproxy.wvu.edu/login.aspx?direct=true \&db=a9h\&AN= 9178958\&site=ehost-live

King, P.M., \& Kitchener, K. S. (Eds.). (1994). Developing reflective judgment: Understanding and promoting intellectual growth and critical thinking in adolescents and adults. San Francisco: Jossey-Bass. 
King, P. M., \& Kitchener, K. S. (2002). The reflective judgment model: Twenty years of research on epistemic cognition. In B. Hofer, \& P. Pintrich (Eds.), Personal epistemology: The psychology of beliefs about knowledge and knowing (pp. 37-61). Mahwah, NJ: Lawrence Earlbaum.

King, P. M., \& Kitchener, K. S. (2004). Reflective judgment: Theory and research on the development of epistemic assumptions through adulthood. Educational Psychologist, 39(1), 5-18. Retrieved from http://search.ebscohost.com/login.aspx?direct=true \&db=a9h\&AN=12526499\&site=ehostlive

King, P. M., \& Magolda, M. B. B. (1996). A developmental perspective on learning. Journal of College Student Development, 37(2), 163-173. Retrieved from http://www.crlt.umich.edu/tstrategies/KingBaxterMagolda1996DevelopmentalPerspectiveonLearning.pdf

King, P. M., \& Magolda, M. B. B. (2005). A developmental model of intercultural maturity. Journal of College Student Development, 46(6), 571-592. doi:10.1353/csd.2005.0060

King, P. M., \& Shuford, B. C. (1996). A multicultural view is a more cognitively complex view. American Behavioral Scientist, 40(2), 153-164. doi:10.1177/0002764296040002006

Kitchener, K. S., Lynch, C. L., Fischer, K. W., \& Wood, P. K. (1993). Developmental range of reflective judgment: The effect of contextual support and practice on developmental stage. Developmental Psychology, 29(5), 893-906. doi:10.1037/0012-1649.29.5.893

Kitchener, K. S., \& Wood, P. K. (1987). Development of concepts of justification in german university students. International Journal of Behavioral Development, 10(2), 171-185. 
Retrieved from http://search.ebscohost.com/login.aspx?direct=true\&db=psyh\&AN=198727777-001\&site=ehost-live

Knowlton, D. S. (2009). Evaluating college students' efforts in asynchronous discussion: A systematic process. In A. Orellana, T. L. Hudgins, \& M. Simonson (Eds.), The perfect online course: Best practices for designing and teaching (pp. 311 - 326). Charlotte: Information Age Publishing, Inc.

Kohlberg, L. (1984). Essays on moral development, Vol. II: The psychology of moral development. San Francisco: Harper \& Row.

Krakovsky, M. (2010). Degrees, distance, and dollars. Communications of the ACM, 53(9), 1819. doi:10.1145/1810891.1810899

Kroll, B. M. (1992). Reflective inquiry in a college english class. Liberal Education, 78(1), 10. Retrieved from http://libproxy.shepherd.edu:2218/login.aspx?direct=true \&db=a9h\&AN=9608042121\&site =ehost-live

Liu, X., Magjuka, R. J., Bonk, C. J., \& Lee, S. (2009). Does sense of community matter: An examination of participants' perceptions of building learning communities in online courses. In A. Orellana, T. L. Hudgins, \& M. Simonson (Eds.), The perfect online course: Best practices for designing and teaching (pp. 127 - 156). Charlotte: Information Age Publishing, Inc. 
Lynch, M. M. (2004). Learning online: A guide to success in the virtual classroom. New York: RoutledgeFalmer.

Maskey, C. L. (2010). An evaluation of the relationship between reflective judgment and critical thinking in senior associate degree nursing students. (Unpublished doctoral dissertation). Indiana University, Indiana.

Mayhew, M. J., \& King, P. (2008). How curricular content and pedagogical strategies affect moral reasoning development in college students. Journal of Moral Education, 37(1), 17-40. doi:10.1080/03057240701803668

Meadows, K. A. (2003). So you want to do research? 4: An introduction to quantitative methods. British Journal of Community Nursing, 8(11), 519-526. Retrieved from http://search.ebscohost.com/login.aspx?direct=true \&db=a9h\&AN=11636011\&site=ehostlive

Miller C. \& Mazur, J. M. (2009). Toward person-centered model of instruction: Can an emphasis on the personal enhance instruction in cyberspace?. In A. Orellana, T. L. Hudgins, \& M. Simonson (Eds.), The perfect online course: Best practices for designing and teaching (pp. 275 - 296). Charlotte: Information Age Publishing, Inc.

Nagel, D. (2009). Most college students to take classes online by 2014. Campus Technology. Retrieved June 13, 2011 from http://campustechnology.com/articles/2009/10/28/mostcollege-students-to-take-classes-online-by-2014.aspx 
O’Malley, J. \& McCraw, H. (1999). Students perceptions of distance learning, online learning, and the traditional classroom. Online Journal of Distance Administration, 2(5), Retrieved July 28, 2011 from http://www.westga.edu/ distance/omalley24.html

Orellana, A. (2009). Class size and interaction in online courses. In A. Orellana, T. L. Hudgins, \& M. Simonson (Eds.), The perfect online course: Best practices for designing and teaching (pp. 127 - 156). Charlotte: Information Age Publishing, Inc.

Parrish, P., \& Linder-VanBerschot, J. (2010). Cultural dimensions of learning: Addressing the challenges of multicultural instruction. International Review of Research in Open \& Distance Learning, 11(2), 1-19. Retrieved from http://search.ebscohost.com.www.libproxy.wvu.edu/login.aspx?direct=true $\& d b=e h h \& A N=$ $51212332 \&$ site=ehost-live

Pascarella, E.T. \& Terenzini, P.T. (1991). How college affects students: Findings and insights from twenty years of research. San Francisco: Jossey-Bass.

Pascarella, E. T. \& Terenzini, P. T. (2005). How college affects students: A third decade of research, volume 2. San Francisco: Jossey-Bass.

Picciano, A. G. (2006). Online learning: Implications for higher education pedagogy and policy. Journal of Thought, 41(1), 75-94. Retrieved from http://search.ebscohost.com/login.aspx?direct=true \&db=ehh\&AN=20001985\&site=ehostlive 
Picciano, A. G., Seaman, J., \& Allen, I. E. (2010). Educational transformation through online learning: To be or not to be. Journal of Asynchronous Learning Networks, 14(4), 17-35. Retrieved from http://search.ebscohost.com/login.aspx?direct=true \&db=ehh\&AN=58718750\&site=ehostlive

Rakes, G. C., \& Dunn, K. E. (2010). The impact of online graduate students' motivation and selfregulation on academic procrastination. Journal of Interactive Online Learning, 9(1), 78-93. Retrieved from http://search.ebscohost.com.www.libproxy.wvu.edu/login.aspx?direct=true $\& d b=e h h \& A N=$ $51471435 \&$ site $=$ ehost-live

Reisetter, M., \& Boris, G. (2009). What works: Student perceptions of effective elements of online learning. In A. Orellana, T. L. Hudgins, \& M. Simonson (Eds.), The perfect online course: Best practices for designing and teaching (pp. 157 -178). Charlotte: Information Age Publishing, Inc.

Robles, M. (2011). History of online education and its impact on business education. In L. G. Snyder (Ed.), Online business education (pp. 1 - 15). Reston: National Business Education Association.

Rogers, P., Graham, C., \& Mayes, C. (2007). Cultural competence and instructional design: Exploration research into the delivery of online instruction cross-culturally. Educational Technology Research \& Development, 55(2), 197-217. doi:10.1007/s11423-007-9033-x 
Ryberg, T. T., \& Larsen, M. C. (2008). Networked identities: Understanding relationships between strong and weak ties in networked environments. Journal Of Computer Assisted Learning, 24(2), 103-115. doi:10.1111/j.1365-2729.2007.00272.x

Sapsford, Roger. (2007). Survey research. London: Sage Publications.

Seaman, J. (2009). Online learning as a strategic asset: The paradox of faculty voices - views and experiences with online learning (Vol. 2). Washington, D.C.: Association of Public and Land-Grant Universities - Sloan National Commission on Online Learning.

Seeleman, C., Suurmond, J., \& Stronks, K. (2009). Cultural competence: A conceptual framework for teaching and learning. Medical Education, 43(3), 229-237. Retrieved from http://search.ebscohost.com.www.libproxy.wvu.edu/login.aspx?direct=true $\& d b=c 8 h \& A N=$ 2010201922\&site=ehost-live

Shambaugh, N. \& Magliaro, S. G. (2006). Instructional design: A systematic approach for reflective practice. Boston: Pearson Education, Inc.

Smith, D. R., \& Ayers, D. F. (2006). Culturally responsive pedagogy and online learning: Implications for the globalized community college. Community College Journal of Research \& Practice, 30(5), 401. doi:10.1080/10668920500442125

Seung-won Yoon, S. R. (2003). In search of meaningful online learning experiences. New Directions for Adult \& Continuing Education, (100), 19-30. Retrieved from http://search.ebscohost.com/login.aspx?direct=true \&db=a9h\&AN=11525048\&site=ehostlive 
Suskie. L. (2004). Assessing student learning: A common sense guide. San Francisco: JosseyBass.

Thorseth, M. (2008). Reflective judgment and enlarged thinking online. Ethics and Information Technology, 10(4), 221-231. Retrieved from http://search.ebscohost.com.www.libproxy.wvu.edu/login.aspx?direct=true\&db=phl\&AN=P HL2129222\&site=ehost-live

Tan, F., Nabb, L., Aagard, S., \& Kim, K. (2010). International ESL graduate student perceptions of online learning in the context of second language acquisition and culturally responsive facilitation. Adult Learning, 21(1), 9-14. Retrieved from http://search.ebscohost.com.www.libproxy.wvu.edu/login.aspx?direct=true \&db=a9h\&AN= 51469680\& site $=$ ehost-live

Ukpokodu, O. N. (2010). Teachers' reflections on pedagogies that enhance learning in an online course on teaching for equity and social justice. Journal of Interactive Online Learning, 9(3), 227-255. Retrieved from http://search.ebscohost.com/login.aspx?direct=true \&db=ehh\&AN=55383106\&site=ehostlive

University of Michigan. (2010). Reflective judgment. Retrieved June 15, 2011 from http://www.umich.edu/ refjudg/index.html

University of Missouri. 2010. Summary of reflective judgment levels. Retrieved March 1, 2010 from http://web.missouri.edu/ woodph/rjstages/rjstages.html. 
U.S. Department of Education, National Center for Education Statistics. (2008). Distance education at degree-granting postsecondary institutions: 2006 - 2007. Retrieved June 13, 2011 from http://nces.ed.gov/pubs2009/2009044.pdf

U.S. Department of Education, Office of Planning, Evaluation, and Policy Development. (2009). Evaluation of evidence-based practices in online learning: A meta-analysis and review of online learning studies. Washington, DC: Author.

Uzuner, S. (2009). Questions of culture in distance learning: A research review. International Review of Research in Open and Distance Learning, 10(3) Retrieved from http://search.ebscohost.com.www.libproxy.wvu.edu/login.aspx?direct=true $\& d b=$ eric $\& A N=$ EJ847781\&site=ehost-live

van Aalst, J \& Katz, S. (1999). [Review of the book Developing reflective judgment: Understanding and promoting intellectual growth and critical thinking in adolescents and adults.] Retrieved August 1, 2011 from http://www.edrev.info/reviews/rev67.htm

van Aalst, J. (2006). Rethinking the nature of online work in asynchronous learning networks. British Journal of Educational Technology, 37(2), 279-288. doi:10.1111/j.14678535.2006.00557.x

Wang, M. (2007). Designing online courses that effectively engage learners from diverse cultural backgrounds. British Journal of Educational Technology, 38(2), 294-311. Retrieved from http://search.ebscohost.com/login.aspx?direct=true \&db=eric\&AN=EJ753252\&site=ehostlive; http://dx.doi.org/10.1111/j.1467-8535.2006.00626.x 
Ward, B. (2010). Cyberstudy: The future? New Zealand Management, 57(6), 52. Retrieved from http://search.ebscohost.com.www.libproxy.wvu.edu/login.aspx direct=true $\& d b=f 5 h \& A N=5$ 2644221\&site=ehost-live

West, E. (2010). Differences in learning styles and satisfaction between traditional face-to-face and online web-based sport management studies students. ProQuest LLC,

Whipp, J., \& Lorentz, R. (2009). Cognitive and social help giving in online teaching: An exploratory study. Educational Technology Research \& Development, 57(2), 169-192. doi:10.1007/s11423-008-9104-7

Whitmire, E. (2004). The relationship between undergraduates' epistemological beliefs, reflective judgment, and their information-seeking behavior. Information Processing \& Management, 40(1), 97. doi:10.1016/S0306-4573(02)00099-7

Wolcott, S. K., \& Lynch, C. L. (1997). Critical thinking in the accounting classroom: A reflective judgment developmental process. Accounting Education (JAI), 2(1), 59. Retrieved from http://search.ebscohost.com/login.aspx $?$ direct=true $\& d b=$ buh $\& A N=9706080809 \&$ site $=$ ehost -live

Wood, P. (1994). A secondary analysis of claims regarding the reflective judgment interview: Internal consistency, sequentiality and intra-individual differences in ill-structured problem solving. Retrieved from http://search.ebscohost.com/login.aspx?direct=true\&db=eric\&AN=ED374156\&site=ehostlive 
Zhao, Y., Le, J., Yah, B., Lai, C., \& Tan, H. (2005). What makes a difference? A practical analysis of research on the effectiveness of distance education. Teachers College Record, 107(8), 1836-1884. Retrieved from http://www.csupomona.edu/ dolce/pdf/online_learning_lit_review.pdf

Zeliff, N. (2011). Delivery options of online education. In L. G. Snyder (Ed.), Online business education (pp. 68 - 81). Reston: National Business Education Association. 
Appendix A - Illustration of Reflective Judgment Model

\begin{tabular}{|c|c|c|c|c|}
\hline Level & Stage & $\begin{array}{c}\text { View of } \\
\text { Knowledge }\end{array}$ & $\begin{array}{l}\text { Concept of } \\
\text { Justification }\end{array}$ & $\begin{array}{c}\text { Typical } \\
\text { Statement }\end{array}$ \\
\hline \multirow{3}{*}{$\begin{array}{l}\text { Pre-Reflective } \\
\text { Thinking } \\
\text { Individuals who } \\
\text { reason in a pre- } \\
\text { reflective fashion } \\
\text { justify their } \\
\text { opinions in a } \\
\text { simple fashion } \\
\text { because they fail } \\
\text { to perceive } \\
\text { answers to the } \\
\text { problem at hand } \\
\text { must contain some } \\
\text { elements of } \\
\text { uncertainty. }\end{array}$} & $\begin{array}{l}\text { Stage 1: } \\
\text { A person knows } \\
\text { that she or he has } \\
\text { observed. Facts and } \\
\text { judgments are not } \\
\text { differentiated. }\end{array}$ & $\begin{array}{l}\text { Knowledge is } \\
\text { assumed to exist } \\
\text { absolutely land } \\
\text { concretely. It can } \\
\text { be obtained with } \\
\text { absolute certainty } \\
\text { through direct } \\
\text { observation. }\end{array}$ & $\begin{array}{l}\text { Beliefs need no } \\
\text { justification since } \\
\text { there is assumed to } \\
\text { be an absolute } \\
\text { correspondence } \\
\text { between what is } \\
\text { believed and what } \\
\text { is true. Alternative } \\
\text { beliefs are not } \\
\text { recognized. }\end{array}$ & $\begin{array}{l}\text { "I know what I } \\
\text { have seen." }\end{array}$ \\
\hline & $\begin{array}{l}\text { Stage 2: } \\
\text { Authorities and } \\
\text { facts are related. } \\
\text { authority figures } \\
\text { are sources of fact } \\
\text { and, therefore, of } \\
\text { truth. }\end{array}$ & $\begin{array}{l}\text { Knowledge is } \\
\text { assumed to be } \\
\text { absolutely certain } \\
\text { or certain but not } \\
\text { immediately } \\
\text { available. } \\
\text { Knowledge can be } \\
\text { obtained directly } \\
\text { through the senses } \\
\text { (as in direct } \\
\text { observation) or via } \\
\text { authority figures. }\end{array}$ & $\begin{array}{c}\text { Beliefs are } \\
\text { unexamined and } \\
\text { unjustified or } \\
\text { justified by their } \\
\text { correspondence } \\
\text { with the beliefs of } \\
\text { an authority figure } \\
\text { (such as a teacher } \\
\text { or parent). Most } \\
\text { issues are assumed } \\
\text { to have a right } \\
\text { answer, so there is } \\
\text { little or no conflict } \\
\text { in making } \\
\text { decisions about } \\
\text { disputed issues. }\end{array}$ & $\begin{array}{l}\text { "If it is on the } \\
\text { news, it has to be } \\
\text { true." }\end{array}$ \\
\hline & $\begin{array}{l}\text { Stage 3: Absolute } \\
\text { answers are } \\
\text { assumed to exist, } \\
\text { but to be } \\
\text { temporarily } \\
\text { inaccessible. In the } \\
\text { absence of absolute } \\
\text { truth, facts and } \\
\text { personal beliefs are } \\
\text { seen as equally } \\
\text { valid. }\end{array}$ & $\begin{array}{l}\text { Knowledge is } \\
\text { assumed to be } \\
\text { absolutely certain } \\
\text { or temporarily } \\
\text { uncertain. In areas } \\
\text { of temporary } \\
\text { uncertainty, only } \\
\text { personal beliefs } \\
\text { can be known until } \\
\text { absolute } \\
\text { knowledge is } \\
\text { obtained. In areas } \\
\text { of absolute } \\
\text { certainty, } \\
\text { knowledge is } \\
\text { obtained from } \\
\text { authorities. }\end{array}$ & $\begin{array}{l}\text { In areas in which } \\
\text { certain answers } \\
\text { exist, beliefs are } \\
\text { justified by } \\
\text { reference to } \\
\text { authorities' views. } \\
\text { In areas in which } \\
\text { answers do not } \\
\text { exist, beliefs are } \\
\text { defended as } \\
\text { personal opinion } \\
\text { since the link } \\
\text { between evidence } \\
\text { and beliefs is } \\
\text { unclear. }\end{array}$ & $\begin{array}{l}\text { "When there is } \\
\text { evidence that } \\
\text { people can give to } \\
\text { convince } \\
\text { everybody one } \\
\text { way or another, } \\
\text { then it will be } \\
\text { knowledge; until } \\
\text { then, it's just a } \\
\text { guess." }\end{array}$ \\
\hline
\end{tabular}




\begin{tabular}{|c|c|c|c|c|}
\hline $\begin{array}{l}\text { Quasi-Reflective } \\
\text { Thinking } \\
\text { Individuals who } \\
\text { reason in the } \\
\text { middle levels of } \\
\text { Reflective } \\
\text { Judgment } \\
\text { recognize that } \\
\text { knowledge claims } \\
\text { about ill-structured } \\
\text { problems contain } \\
\text { elements of } \\
\text { uncertainty; thus, } \\
\text { there is an } \\
\text { understanding that } \\
\text { some situations are }\end{array}$ & $\begin{array}{l}\text { Stage 4: Evidence } \\
\text { is now seen as } \\
\text { important to the } \\
\text { construction of } \\
\text { knowledge claims, } \\
\text { along with the } \\
\text { acknowledgment } \\
\text { that a belief cannot } \\
\text { be known with } \\
\text { absolute certainty } \\
\text { for pragmatic } \\
\text { reasons. Thus, } \\
\text { knowledge claims } \\
\text { are idiosyncratic to } \\
\text { the individual. }\end{array}$ & $\begin{array}{l}\text { Knowledge is } \\
\text { uncertain and } \\
\text { knowledge claims } \\
\text { are idiosyncratic to } \\
\text { the individual } \\
\text { because of } \\
\text { situational } \\
\text { variables (e.g., } \\
\text { incorrect reporting } \\
\text { of data, data lost } \\
\text { over time, or } \\
\text { disparities in } \\
\text { access to } \\
\text { information; these } \\
\text { factors dictate that } \\
\text { any knowledge } \\
\text { claim contains an } \\
\text { element of } \\
\text { uncertainty. }\end{array}$ & $\begin{array}{l}\text { Since there is no } \\
\text { source of certainty } \\
\text { for one's beliefs, } \\
\text { beliefs are justified } \\
\text { by giving reasons } \\
\text { that are often } \\
\text { idiosyncratic, such } \\
\text { as choosing } \\
\text { evidence that fits } \\
\text { an established } \\
\text { belief. }\end{array}$ & $\begin{array}{l}\text { "I'd be more } \\
\text { including to } \\
\text { believe evolution } \\
\text { if they had proof. } \\
\text { It's just like the } \\
\text { pyramids: I don't } \\
\text { think we'll ever } \\
\text { know. Who are } \\
\text { you going to ask? } \\
\text { No one was there." }\end{array}$ \\
\hline $\begin{array}{l}\text { The difficulty is in } \\
\text { understanding how } \\
\text { judgments ought } \\
\text { to be made in light } \\
\text { of this uncertainty. } \\
\text { Often, individuals } \\
\text { believe that while } \\
\text { judgments ought } \\
\text { to be based on } \\
\text { evidence, } \\
\text { valuation is } \\
\text { individualistic and } \\
\text { idiosyncratic. } \\
\text { While they can } \\
\text { acknowledge } \\
\text { differences } \\
\text { between well- and } \\
\text { ill-structured } \\
\text { problems, they are } \\
\text { often at a loss } \\
\text { when asked to } \\
\text { solve ill-structured } \\
\text { problems because } \\
\text { they don't know } \\
\text { how to deal with } \\
\text { the inherent } \\
\text { ambiguity of such } \\
\text { problems. }\end{array}$ & $\begin{array}{l}\text { Stage 5: Types of } \\
\text { evidence are } \\
\text { differentiated } \\
\text { within perspectives } \\
\text { (e.g., historical or } \\
\text { scientific } \\
\text { evidence). Further, } \\
\text { different rules of } \\
\text { inquiry across } \\
\text { perspectives or } \\
\text { disciplines are } \\
\text { recognized. Quality } \\
\text { of evidence is also } \\
\text { evaluated as } \\
\text { strong/weak, } \\
\text { relevant/irrelevant, } \\
\text { etc. Evidence is not } \\
\text { an end in itself, but } \\
\text { is used to construct } \\
\text { interpretations. }\end{array}$ & $\begin{array}{l}\text { Knowledge is seen } \\
\text { as contextual and } \\
\text { subjective. Since it } \\
\text { is filtered through } \\
\text { a person's } \\
\text { perceptions and } \\
\text { criteria for } \\
\text { judgment, only } \\
\text { interpretations of } \\
\text { evidence may be } \\
\text { known. }\end{array}$ & $\begin{array}{l}\text { Beliefs are } \\
\text { justified within a } \\
\text { particular context } \\
\text { using the rules of } \\
\text { inquiry for that } \\
\text { context, with the } \\
\text { understanding that } \\
\text { justification is } \\
\text { context-specific or } \\
\text { that beliefs are } \\
\text { balanced against } \\
\text { each other. Each } \\
\text { approach has the } \\
\text { effect of } \\
\text { complicating and } \\
\text { delaying } \\
\text { judgments. }\end{array}$ & $\begin{array}{l}\text { "People think } \\
\text { differently and so } \\
\text { they attack the } \\
\text { problem } \\
\text { differently. Other } \\
\text { theories could be } \\
\text { as true as my own, } \\
\text { but based on } \\
\text { different } \\
\text { evidence." }\end{array}$ \\
\hline
\end{tabular}




\begin{tabular}{|c|c|c|c|c|}
\hline $\begin{array}{l}\text { Reflective } \\
\text { Thinking } \\
\text { The reasoning } \\
\text { typified in levels } 6 \\
\text { and } 7 \text { reflects the } \\
\text { epistemological } \\
\text { assumption that } \\
\text { one's } \\
\text { understanding of } \\
\text { the world is not } \\
\text { "given" but must } \\
\text { be actively } \\
\text { constructed and } \\
\text { that knowledge } \\
\text { must be } \\
\text { understood in } \\
\text { relationship to the } \\
\text { context in which it } \\
\text { was generated. An } \\
\text { additional } \\
\text { assumption is that }\end{array}$ & $\begin{array}{l}\text { Stage 6: } \\
\text { Generalized rules } \\
\text { of inquiry may be } \\
\text { applied across } \\
\text { perspective (e.g., } \\
\text { the weight of the } \\
\text { argument, } \\
\text { likelihood of the } \\
\text { conclusion being } \\
\text { correct, and } \\
\text { acknowledgment } \\
\text { that judgments are } \\
\text { tentative). } \\
\text { Interpretations are } \\
\text { subject to critique } \\
\text { and dogmatic for } \\
\text { coherency, } \\
\text { consistency with } \\
\text { the evidence, } \\
\text { explanatory power, } \\
\text { etc. }\end{array}$ & $\begin{array}{l}\text { Knowledge is } \\
\text { personally } \\
\text { constructed from a } \\
\text { variety of sources, } \\
\text { based on one's } \\
\text { own and others } \\
\text { evaluations of } \\
\text { evidence, others' } \\
\text { conclusions, etc. }\end{array}$ & $\begin{array}{l}\text { Beliefs are } \\
\text { justified by } \\
\text { comparing } \\
\text { evidence and } \\
\text { opinion on } \\
\text { different sides of } \\
\text { an issue or across } \\
\text { contexts, and by } \\
\text { constructing } \\
\text { solutions that are } \\
\text { evaluated by } \\
\text { personally- } \\
\text { endorsed criteria, } \\
\text { such as one's } \\
\text { personal values or } \\
\text { the pragmatic need } \\
\text { for action. }\end{array}$ & $\begin{array}{l}\text { "It's very difficult } \\
\text { in this life to be } \\
\text { sure. There are } \\
\text { degrees of } \\
\text { sureness. You } \\
\text { come to a point at } \\
\text { which you are sure } \\
\text { enough for a } \\
\text { personal stance on } \\
\text { an issue." }\end{array}$ \\
\hline $\begin{array}{l}\text { some } \\
\text { interpretations or } \\
\text { knowledge claims } \\
\text { may be judged as } \\
\text { more plausible } \\
\text { than others. Thus, } \\
\text { while absolute } \\
\text { truth will never be } \\
\text { ascertained with } \\
\text { complete certainty, } \\
\text { some views may } \\
\text { be evaluated as } \\
\text { more reasonable } \\
\text { explanations. This } \\
\text { view presumes } \\
\text { that judgments } \\
\text { must not only be } \\
\text { grounded in } \\
\text { relevant data, but } \\
\text { that they must also } \\
\text { be evaluated to } \\
\text { determine their } \\
\text { validity. }\end{array}$ & $\begin{array}{l}\text { Stage 7: } \\
\text { Judgments are seen } \\
\text { as the outcome of a } \\
\text { process of rational } \\
\text { inquiry; they are } \\
\text { based on a variety } \\
\text { of interpretive } \\
\text { considerations } \\
\text { (e.g., the } \\
\text { explanatory value } \\
\text { of the } \\
\text { interpretations, the } \\
\text { risks of an } \\
\text { erroneous } \\
\text { conclusion, and } \\
\text { consequences of } \\
\text { alternative } \\
\text { judgments) and the } \\
\text { interrelationships } \\
\text { of these factors. }\end{array}$ & $\begin{array}{l}\text { Knowledge is } \\
\text { constructed using } \\
\text { the process of } \\
\text { reasonable inquiry } \\
\text { for constructing a } \\
\text { well-informed } \\
\text { understanding of } \\
\text { the problem at } \\
\text { hand. }\end{array}$ & $\begin{array}{c}\text { Beliefs are } \\
\text { justified } \\
\text { probabilistically } \\
\text { using evidence and } \\
\text { arguments; } \\
\text { conclusions are } \\
\text { defended as } \\
\text { representing the } \\
\text { most complete, } \\
\text { most compelling, } \\
\text { or most plausible } \\
\text { understanding of } \\
\text { an issue available } \\
\text { to date, based on } \\
\text { the current } \\
\text { evidence. }\end{array}$ & $\begin{array}{l}\text { "One can judge } \\
\text { arguments by how } \\
\text { well thought out } \\
\text { the positions are, } \\
\text { what kinds of } \\
\text { reasoning and } \\
\text { evidence are used } \\
\text { to support it, and } \\
\text { how consistent the } \\
\text { way one argues on } \\
\text { this topic is as } \\
\text { compared with } \\
\text { other topics." }\end{array}$ \\
\hline
\end{tabular}

Summary of reflective judgment levels. (n.d.). Retrieved March 1, 2010 from http://web.missouri.edu/ woodph/rjstages/rjstages.html. 
Appendix B - Illustrated Sample of Reasoning about Critical Issues Assessment

\section{Artificial Sweeteners}

People often have to make decisions that may affect their health such as deciding whether to eat foods or drink beverages that contain artificial sweeteners. There have been conflicting reports about the safety of these additives. For example, some studies have indicated that even in small amounts, artificial sweeteners (such as Nutrasweet) can cause health problems, making foods containing them unsafe to eat. Other studies, however, have indicated that even in large amounts, artificial sweeteners do not cause health problems, and that the foods containing them are safe to eat.

1. Please indicate your personal opinion on this issue: I think that artificial sweeteners:

Are not safe for people to eat

2. How is it possible that researchers in the same field disagree about whether a particular artificial sweetener is harmful? (Please write your answer on the lines provided.)

3. Many people have heard about disagreements among researchers about this, and they suggest different reasons why that might happen. How similar is each of the following reasons to your own understanding of why researchers disagree? (Darken the Appropriate Cirde.)

$V S=$ Very Similar, $S=$ Similar, $D=$ Dissimilar, $V D=$ Very Dissimilar, $M=$ Meaningless

(v) (D) (M) A. Researchers who are honest will not disagree about whether a particular artificial sweetener is harmful.

(VS) (S) (DD) B. Researchers disagree about this issue because, like everyone else, they are confused about the safety of artificial sweeteners. Therefore it is my perspective that what they conclude is just their opinion.

(VS) (D) (MD C. Researchers disagree whether enough studies have been done that show artificial sweeteners are safe or that these chemicals are not safe.

(vS) (D) (DD D. Researchers disagree because of the different ways they were brought up and/or the different schools they attended.

(VS) (D) (DD E. Researchers disagree because they approach the issue with different opinions already in mind about whether additives are safe. As a result, they conduct studies to support their view.

(v) (S) (D) (M. F. Researchers arrive at different conclusions because the evidence itself is complex and they examine it from several perspectives. They arrive at a decision by synthesizing their knowledge, experiences, and expert opinions.

(VS) (D) (D) G. Researchers might say that one view about the safety of a sweetener was better, but they would also say that this viewpoint is relative to a particular way of understanding this issue.

(VS)(D) (DD) H. Researchers disagree because the premeditated hard evidence is synthesized into available belief systems about different comprehensive factual analyses.

(ㄱ) (D) (D) I. Researchers disagree because they are really studying different facets of the issue and the best ways to address one facet of the issue are different than the best ways to address other facets.

(VS)(D) (II) J. Researchers disagree because their evaluation of the evidence leads them to defend different conclusions. Some researchers conclusions are more reasonable, however, and reflect a more comprehensive synthesis of the available information.

4. Please rank the statements above (A, B, C., etc.) that are most similar to your thinking. Please check only one statement per line. If no statement beyond one or two is at all like your thinking, check the box labeled "None of These" on the appropriate line(s).

Statement (A) (B) (C) (D) (E) F G (H) (I) (J) most like how I think.

Statement (A) (B) (C) (D) (E) F (G) (H) II (J) None of These is second most like how I think.

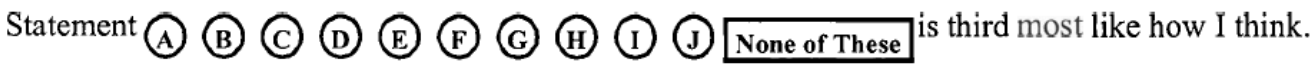


Appendix C - Promoting Reflective Thinking

\begin{tabular}{|c|c|}
\hline \multicolumn{2}{|c|}{ Promoting Reflective Thinking } \\
\hline \multicolumn{2}{|c|}{ Stage 2} \\
\hline \multirow{3}{*}{$\begin{array}{l}\text { Difficulties } \\
\text { Recognizing that there are legitimate } \\
\text { differences of opinion about some issues. } \\
\text { Giving reasons for a belief beyond reference to } \\
\text { an authority's view. }\end{array}$} & Sample assignments \\
\hline & $\begin{array}{l}\text { Provide arguments on two sides of an issue, } \\
\text { giving reasons for the arguments }\end{array}$ \\
\hline & $\begin{array}{l}\text { Identify the evidence for different views on the } \\
\text { same issue. }\end{array}$ \\
\hline $\begin{array}{l}\text { Accepting that even authorities do not have } \\
\text { right or wrong answers for some issues. }\end{array}$ & $\begin{array}{l}\text { Consider the views of different experts on a } \\
\text { particular event. }\end{array}$ \\
\hline \multicolumn{2}{|c|}{ Stage 3} \\
\hline \multirow{2}{*}{$\begin{array}{l}\text { Difficulties } \\
\text { Recognizing legitimate sources of authority as } \\
\text { better qualified than themselves in making a } \\
\text { judgment about a controversial issue. }\end{array}$} & Sample assignments \\
\hline & $\begin{array}{l}\text { Here is one point of view on an issue. What } \\
\text { are other perspectives on this issue? Cite } \\
\text { evidence for each perspective. }\end{array}$ \\
\hline \multirow{2}{*}{$\begin{array}{l}\text { Understanding the difference between } \\
\text { interpretation and opinion. } \\
\text { Using evidence to justify a point of view. } \\
\text { Appreciating multiple evidence-based } \\
\text { perspectives on a single issue. }\end{array}$} & $\begin{array}{l}\text { Critique a specified point of view, paying } \\
\text { particular attention to the use of evidence. }\end{array}$ \\
\hline & $\begin{array}{l}\text { Defend a specified point of view, giving the } \\
\text { best evidence you can find in support of it. }\end{array}$ \\
\hline \multicolumn{2}{|l|}{1} \\
\hline \multirow{4}{*}{$\begin{array}{l}\text { Difficulties } \\
\text { Understanding that the nature of knowing itself } \\
\text { leads to the uncertainty of knowledge. } \\
\text { Understanding that all points of view are not } \\
\text { equally valid and that opinion should be based } \\
\text { on evidence. } \\
\text { Understanding that different perspectives may } \\
\text { lead to different legitimate interpretations of } \\
\text { evidence but that this is not the same as bias. } \\
\text { Understanding the difference between facts } \\
\text { and interpretations. }\end{array}$} & Sample assignments \\
\hline & $\begin{array}{l}\text { Compare good and bad arguments on one side } \\
\text { of an issue; evaluate the adequacy of these } \\
\text { arguments by looking at the evidence and how } \\
\text { it is interpreted and noting what makes a } \\
\text { stronger argument. }\end{array}$ \\
\hline & $\begin{array}{l}\text { Here are two conflicting points of view on an } \\
\text { issue. Explain how the author of each arrived } \\
\text { at his or her conclusions. Pay careful attention } \\
\text { to the academic discipline or perspective from } \\
\text { which the issue was approached. }\end{array}$ \\
\hline & $\begin{array}{l}\text { Distinguish between evaluating the adequacy } \\
\text { of arguments and making judgments about } \\
\text { people. }\end{array}$ \\
\hline
\end{tabular}




\begin{tabular}{|c|c|}
\hline \multicolumn{2}{|c|}{ Stage 5} \\
\hline \multirow{3}{*}{$\begin{array}{l}\text { Difficulties } \\
\text { Choosing among competing evidence-based } \\
\text { interpretations. } \\
\text { Explaining relationship between alternative } \\
\text { perspectives on an issue. } \\
\text { Recognizing that choosing one alternative does } \\
\text { not deny the legitimacy of other alternatives. }\end{array}$} & Sample assignments \\
\hline & $\begin{array}{l}\text { Compare and contrast two competing (and } \\
\text { equal) points of view, citing and evaluating } \\
\text { evidence and arguments used by proponents of } \\
\text { each. Determine which proponent makes the } \\
\text { better interpretations of the given evidence and } \\
\text { which conclusion is stronger. }\end{array}$ \\
\hline & $\begin{array}{l}\text { Here are two conflicting points of view on the } \\
\text { same issue. Explain how each author arrived } \\
\text { at his or her conclusions. Identify the evidence } \\
\text { and arguments for each point of view, } \\
\text { suggesting which has stronger support. } \\
\text { Explain which view you would endorse and } \\
\text { why you would do so. }\end{array}$ \\
\hline \multicolumn{2}{|c|}{ Stage 6} \\
\hline \multirow{3}{*}{$\begin{array}{l}\text { Difficulties } \\
\text { Understanding that even though knowledge } \\
\text { may change at some future point, some } \\
\text { principles or procedures are currently } \\
\text { generalizable beyond the immediate situation. } \\
\text { Constructing one's own point of view and } \\
\text { defending it on the basis of evidence or } \\
\text { argument as being better (for example, having } \\
\text { greater truth value) than other points of view. }\end{array}$} & Sample assignments \\
\hline & $\begin{array}{l}\text { Develop and defend firm arguments for a } \\
\text { particular point of view, perhaps in conjunction } \\
\text { with our own research. }\end{array}$ \\
\hline & $\begin{array}{l}\text { Provide your own organization of a given field } \\
\text { of study (for example, concept mapping of a } \\
\text { course or a discipline), with explicit reference } \\
\text { to the interrelationships between elements. }\end{array}$ \\
\hline
\end{tabular}

(Adapted from King \& Kitchener, 1994, p. 250 - 254) 
Appendix D - Institutional Review Board at West Virginia University Approval

\section{W. WestVirginiaUniversity. \\ Office of Research Compliance}

\section{IRB Protocol-Exemption}

$\begin{array}{ll}\text { To: } & \text { Diaz, Sebastian } \\ \text { From: } & \text { WVU Office of Research Compliance } \\ \text { Date: } & \text { Thursday, November 17, 2011 } \\ \text { Subject: } & \text { Exemption Acknowledgement } \\ & \\ \text { Tracking \#: } & \text { H-23521 } \\ \text { Title: } & \begin{array}{l}\text { Comparing Student Stage of Reflective Judgment between Traditional } \\ \text { and Online Academic Programs of Study }\end{array}\end{array}$

The above-referenced study was reviewed by the West Virginia University Institutional Review Board (IRB) and was granted exemption in accordance with 45 CFR 46.101(2).

This protocol was reviewed using the following:

Exemption Checklist (210r)

This research study was granted an exemption because the Research involves educational tests, survey procedures, interview procedures or observation of public behavior and (i) information obtained is recorded in such a manner that human subjects cannot be identified, directly or through identifiers linked to the subjects; and (ii) any disclosure of the human subjects' responses outside the research could not reasonably place the subjects at risk of criminal or civil liability or be damaging to the subjects' financial standing, employability, or reputation [45 CFR 46.101(2)].

All exemptions are only good for three years. If this research extends more than three years beyond the approved date, then the researcher will have to request another exemption.

The following documents have been acknowledged for use in this study and are available in the BRAAN system:

Surveys, Questionnaires, Interviews

Attachments

$\mathrm{RCl}$-sample-dilemma.pdf Sample of questionnaire is attached.

Miscellaneous Attachments 
Attachments

Cover Letter for Miller Study.pdf This document contains the cover letter to be provided to participants in the study.

Email to Participating Institution.pdf This document provides the body of the email to be sent to institutions who might be participating in the study.

Thank you.

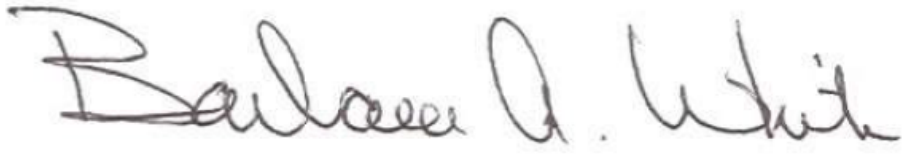

Board Designee: White, Barbara

Letter Sent By: White, Barbara, 11/17/2011 2:25 PM

Once you begin your human subject research, the following regulations apply:

1. Any modifications to the study protocol must be reviewed and acknowledged by the IRB prior to implementation.

2. You may not use a modified form until it has been acknowledged by the IRB. 
Appendix E - Amendment Approval

\section{WestVirginiaUniversity.}

\section{Office of Research Compliance}

\section{Amendment - Exemption}

To: $\quad$ Diaz, Sebastian

From: $\quad$ WVU Office of Research Compliance

Date: $\quad$ Thursday, February 16, 2012

Subject: No action required

Tracking \#: AMEND-3553 (H-23521)

Title: $\quad$ Comparing Student Stage of Reflective Judgment between Traditional and Online Academic Programs of Study

On $2 / 16 / 2012$ the following changes to the study were reviewed and approved:

There are three changes we'd like to make. The first is that we would like to increase the number of universities participating in the study to up to 15 institutions, depending on their willingness to participate. The second amendment concerns how to identify a respondent as either junior or senior, and online or face-to-face. Originally, we were going to incorporate this as direct survey items. Given the limitations of the survey, however, we now need to instruct the respondents from a given institution to all use a code that identifies the institution, the junior/senior status, and the online/face-to-face status. The students' identities will still remain confidential. The third change involves the wording of the email invitation to take the anonymous online survey. Exempt Research Checklist (210r)

The above-referenced study was granted exemption in accordance with 45 CFR 46.101 (2).

Thank you.

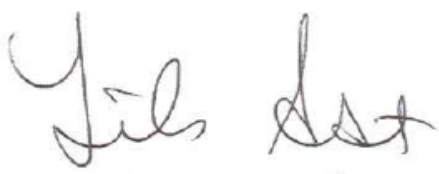

Board Designee: Ast, Lilo

Letter Sent By: Ast, Lilo, 2/16/2012 3:27 PM 
Appendix F - Student Invitation Letter

Dear Participant,

This letter is a request for you to take part in a research project and provide valuable information to assess how the phenomenon of "reflective judgment" plays out in business-related undergraduate programs. This project is being conducted by R. Craig Miller, doctoral student in Educational Leadership Studies at West Virginia University and Co-I with supervision of Dr. Sebastian Diaz, an Assistant Professor in the College of Human Resources and Education and PI for this research.

Your participation in this project is greatly appreciated and will take approximately 30 minutes to complete the questionnaire at this link http://www.reflectivejudgment.org. In the log in box, please select Academic Program of Delivery Comparison for your institution. Your password for this item is windlass.

Choose your subject identification from this list:

- Juniors, please enter: tjunior6

- Seniors, please enter: tsenior6

All data will be reported in the aggregate. Neither your name, student identification, nor other identifiable information will be requested. Your involvement in this project will be kept as confidential as legally possible. You must be 18 years of age or older to participate. I will not ask any information that should lead back to your identity as a participant. Your participation is completely voluntary. Your class standing will not be affected if you decide either not to participate or to withdraw. West Virginia University's Institutional Review Board acknowledgement of this project is on file.

I hope that you will participate in this research project, as it could be beneficial in understanding the impact reflective judgment of students enrolled in business-related undergraduate programs of study. Should you have any questions about this letter or the research project, please feel free to contact R. Craig Miller at (304) 283 - 3194 or by e-mail at rmille34@mix.wvu.edu.

Thank you for your time and help with this project.

Sincerely,

R. Craig Miller

(http://www.reflectivejudgment.org)

Select - Academic Program of Delivery Comparison

Enter the following password: windlass 